\title{
Allergen presensitization drives an eosinophil- dependent arrest in lung-specific helminth development
}

\author{
Pedro H. Gazzinelli-Guimaraes, ${ }^{1}$ Rafael de Queiroz Prado, ${ }^{1}$ Alessandra Ricciardi, ${ }^{1}$ Sandra Bonne-Année, ${ }^{1}$ Joshua Sciurba,, \\ Erik P. Karmele, ${ }^{1,2}$ Ricardo T. Fujiwara, ${ }^{3}$ and Thomas B. Nutman ${ }^{1}$ \\ 'Laboratory of Parasitic Diseases, National Institute of Allergy and Infectious Diseases, NIH, Bethesda, Maryland, USA. nstitute for Biomedical Sciences, The George Washington University, Washington, DC, \\ USA. ${ }^{3}$ Department of Parasitology, Institute of Biological Sciences (ICB), Universidade Federal de Minas Cerais, Belo Horizonte, Brazil.
}

\begin{abstract}
This study investigates the relationship between helminth infection and allergic sensitization by assessing the influence of preexisting allergy on the outcome of helminth infections, rather than the more traditional approach in which the helminth infection precedes the onset of allergy. Here we used a murine model of house dust mite-induced (HDM-induced) allergic inflammation followed by Ascaris infection to demonstrate that allergic sensitization drives an eosinophil-rich pulmonary type 2 immune response (Th2 cells, M2 macrophages, type 2 innate lymphoid cells, IL-33, IL-4, IL-13, and mucus) that directly hinders larval development and reduces markedly the parasite burden in the lungs. This effect is dependent on the presence of eosinophils, as eosinophil-deficient mice were unable to limit parasite development or numbers. In vivo administration of neutralizing antibodies against CD4 prior to HDM sensitization significantly reduced eosinophils in the lungs, resulting in the reversal of the HDM-induced Ascaris larval killing. Our data suggest that HDM allergic sensitization drives a response that mimics a primary Ascaris infection, such that CD4+ Th2-mediated eosinophil-dependent helminth larval killing in the lung tissue occurs. This study provides insight into the mechanisms underlying tissue-specific responses that drive a protective response against the early stages of the helminths prior to their establishing long-lasting infections in the host.
\end{abstract}

\section{Introduction}

Helminth parasites are well known for their capacity to modulate the parasite-directed host immune response $(1,2)$; with long-standing infection these parasites modulate the host response to bystander antigens/pathogens (3-5), to allergic diseases $(6,7)$, and to both orally and parenterally administered vaccines $(8,9)$. More controversially and largely on the basis of murine models, helminths have been implicated in ameliorating the severity of inflammatory bowel disease $(10,11)$, diabetes $(12,13)$, and arthritis (14), findings that have driven the concept of using these parasites or their excreted/secreted products, including their extracellular vesicles $(15)$, for the treatment of inflammatory diseases $(16,17)$. However, the mechanisms by which helminths mediate these protective functions remained poorly defined.

Other studies, in contrast, have indicated that infection by helminths, more specifically by Ascaris lumbricoides, is associated with an increased incidence of allergic reactions (18-20) and that the presensitization to Ascaris antigens accelerates mite-specific $\operatorname{IgE}$ response upon mite antigen inhalation in murine models (21). More recently, it has been suggested that Ascaris larval migration in the lungs induces severe allergic airway disease in mice (22).

Conflict of interest: The authors have declared that no conflict of interest exists. Copyright: @ 2019, American Society for Clinical Investigation.

Submitted: February 5, 2019; Accepted: June 11, 2019; Published: August 5, 2019. Reference information: J Clin Invest. 2019;129(9):3686-3701.

https://doi.org/10.1172/JCI127963.
Studies to date have attempted to elucidate the mechanisms underlying the regulation of allergic diseases by helminth infection (23). Helminth infections induce IL-10 responses in the host, which have been hypothesized to be a central mediator in regulating allergic diseases (24). The helminth-induced IL-10 directly modulates allergen-specific $\mathrm{CD}^{+}$effector responses $(25,26)$ or indirectly alters the $\operatorname{IgG} 4 / \operatorname{IgE}$ balance in favor of $\operatorname{IgG} 4(27,28)$. Both allergic disorders and helminth infections share an association with type 2 immune responses, characterized by the production of IL-4, IL-5, IL-9, IL-10, and IL-13, induction of IgG4 and IgE antibodies, and tissue and peripheral blood eosinophilia $(29,30)$. This type 2-associated immune response that drives an eosinophildominated environment has been implicated in protection against helminth infection but has also been shown to play a key role in the pathogenesis of allergic diseases $(26,31)$. The ability of eosinophils to control parasite levels has been extensively discussed in the literature over the last few decades (32), mainly in the context of primary, concomitant, or secondary infections (reinfection) using irradiated Onchocerca volvulus larvae (33), Trichinella spiralis larvae (34), Nippostrongylus brasiliensis and Heligmosomoides polygyrus adult worms (35), and Brugia malayi microfilariae (36) as models. In most cases of eosinophil-mediated killing of helminth larvae, the mechanisms underlying the helminth killing appear to involve either antibody-induced or complementinduced release of toxic eosinophil granule proteins and/or reactive oxygen intermediates by activated eosinophils (37) or in conjunction with other innate cells such as neutrophils (38). 
A

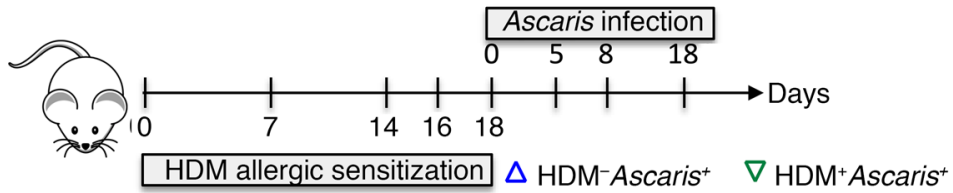

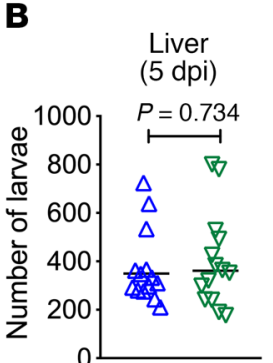

C $\begin{gathered}\text { Lung tissue } \\ (5 \mathrm{dpi})\end{gathered}$
50.
40.
30.
20.
10.
0

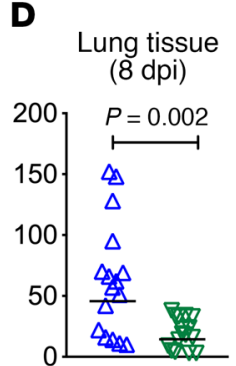

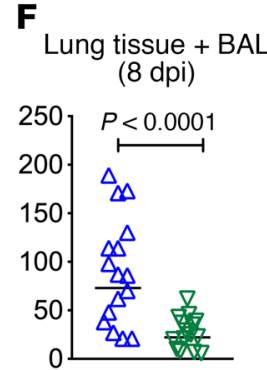

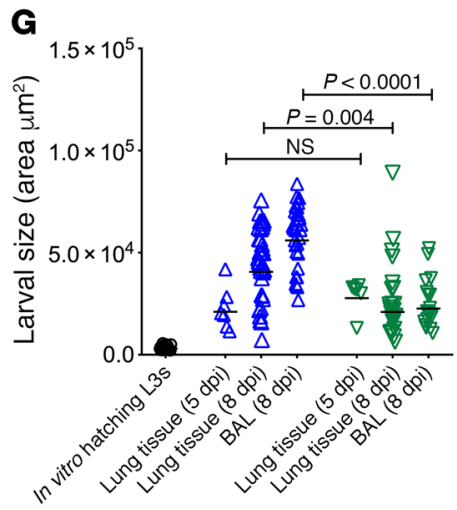

H
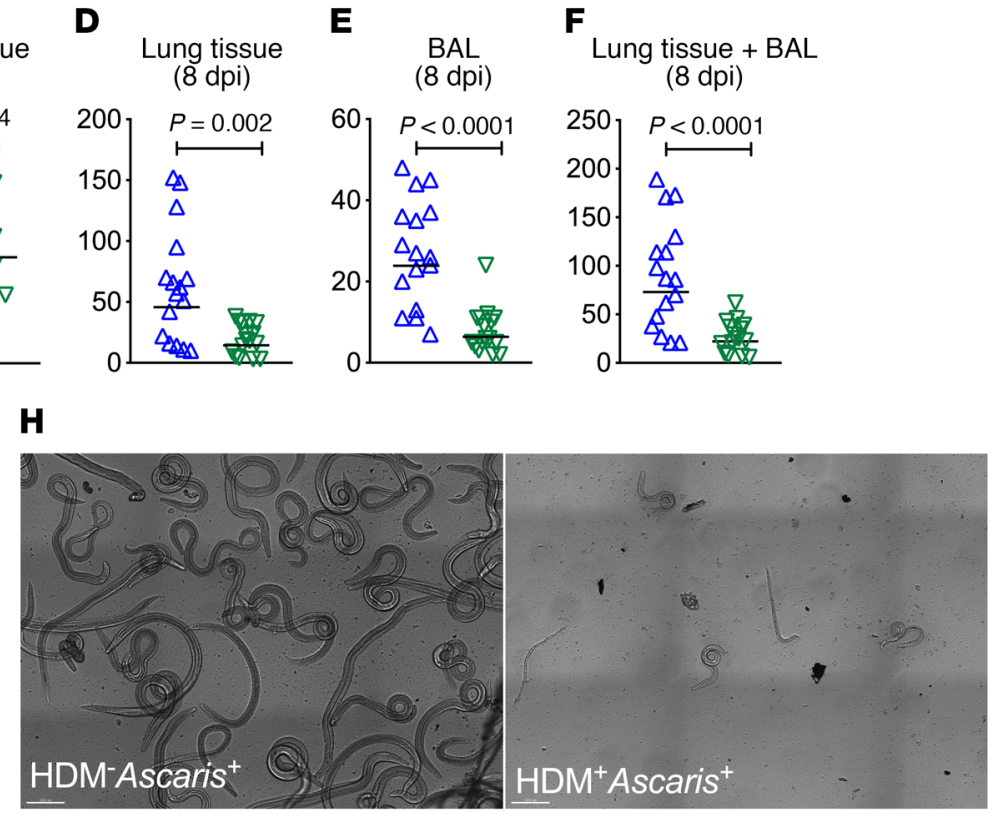

Figure 1. HDM sensitization followed by Ascaris infection limits the parasite burden by impairing larval development in the lungs. (A) Experimental design scheme for HDM allergic sensitization followed by Ascaris infection. (B-C) Parasite burden in the liver (B) and lungs at different time points of evaluation (C-F), as well as lung-stage larval development by morphometric analysis of larvae recovered from $\mathrm{HDM}^{-}$Ascaris $^{+}$and $\mathrm{HDM}^{+}$Ascaris ${ }^{+} \mathrm{BALB} / \mathrm{c}$ mice (C). (H) Representative bright confocal image of the larvae recovered in the BAL at day 8 of infection (scale bars: $200 \mu \mathrm{m}$ ). Each symbol represents a single mouse, and the horizontal bars are the geometric means (GMs). $P$ values are indicated on each graph. Three independent experiments were performed. Differences between $\mathrm{HDM}^{-}$Ascaris ${ }^{+}\left(n=17\right.$ mice total) and $\mathrm{HDM}^{+}$Ascaris ${ }^{+}(n=17$ mice total) groups were considered statistically significant at $P<0.05$ by unpaired Mann-Whitney test. Kruskal-Wallis test followed by Dunn's multiple-comparisons test was used for $\mathbf{G}$.

Human population shifts have led to a reexamination of how helminth infections and allergy interface given that for many people allergic sensitization has preceded the acquisition of the helminth infection. Indeed, we have previously demonstrated that allergic sensitization to house dust mites (HDM), an environmental allergen, prior to the acquisition of a human filarial infection induces a markedly exaggerated parasite antigen-specific Th2-associated immune response (39). We hypothesized that this exaggerated type 2-dominated immune response could play a vital role in limiting parasite burden at the expense of parasite-associated morbidity.

Using the HDM model of murine allergic asthma inflammation and Ascaris spp. infection, we sought to identify the underlying mechanisms of how preexisting allergic sensitization influences the outcome of Ascaris infection. We found that sensitization with HDM impairs Ascaris migration and development through the underlying type 2-dominated, eosinophil-rich inflammation. Here, we dissect the mechanism by which allergic sensitization protects the host from helminth infection, highlighting how tissue-specific responses may control the early stages of helminth parasites before they establish long-lasting infections in the host.

\section{Results}

HDM sensitization followed by Ascaris infection inhibits larval development and reduces numbers of parasites in the lungs. It has been shown quite convincingly that the early Ascaris larval migration through the organs (termed larval ascariasis) in mice mimics with a certain degree of rigor what happens in acute infection of pigs and humans (definitive hosts), in terms of both the pattern of larval migration (40-42) and the highly polarized Th2 immune response in the lung $(43,44)$.

To determine whether pre-established pulmonary allergic inflammation driven by HDM alters the nature of a lung-migrating helminth infection, we examined larval migration to the liver (day 5) and to the lungs 5,8 , and 18 days postinfection (dpi) (Figure 1A). Our data show that at day 5 after Ascaris infection, HDM sensitization prior to infection $\left(\mathrm{HDM}^{+}\right.$Ascaris $\left.{ }^{+}\right)$did not affect the numbers of migrating larvae to the liver (Figure 1B) or to the lungs (Figure 1C). By $8 \mathrm{dpi}$, in contrast, there was a $70 \%$ reduction in the total worm burden in the lungs/bronchoalveolar lavage (BAL) of $\mathrm{HDM}^{+}$Ascaris $^{+}$mice compared with HDM-unsensitized Ascarisinfected mice $\left(\mathrm{HDM}^{-}\right.$Ascaris $\left.{ }^{+}\right)$(Figure 1, D-F). Moreover, larvae 
isolated from the lungs and BAL fluid of the $\mathrm{HDM}^{+}$Ascaris ${ }^{+}$mice displayed significant reduction in size compared with larvae from $\mathrm{HDM}^{-}$Ascaris $^{+}$(Figure 1, G and H), suggesting that HDM sensitization followed by Ascaris infection inhibits larval development and reduces numbers of parasites in the lungs. Notably, at $18 \mathrm{dpi}$ there were no more larvae in the lungs, as all animals typically clear the infection by day $14 \mathrm{dpi}$.

Increased leukocyte infiltration, mucus production, and type 2 immune profile in the lungs of $\mathrm{HDM}^{+}$Ascaris $^{+}$mice. We hypothesized that the HDM-driven lung inflammation was limiting the parasite burden and larval development in $\mathrm{HDM}^{+}$Ascaris ${ }^{+}$mice. To test this hypothesis, we first evaluated the changes in the lung tissue by examining the infiltration of inflammatory cells into the lungs, the levels of chemokines that might underlie some of the cell migration into the lung tissue, the mucus production by epithelial cells in the airways, and the cytokine signature in the lung tissue. Sensitization with HDM followed by Ascaris infection $\left(\mathrm{HDM}^{+}\right.$Ascaris $\left.{ }^{+}\right)$ caused a marked influx of inflammatory cells (leukocytes) to the lung tissue, in comparison with $\mathrm{HDM}^{-}$Ascaris ${ }^{+}$mice at 5 and $8 \mathrm{dpi}$. Interestingly, the HDM-induced cellularity in the lungs returned to baseline 18 days after the last sensitization. The number of leucocytes in the lungs (Figure 2A) as well as the histological analysis of the lung tissue, at $8 \mathrm{dpi}$, revealed an intense perivascular and peribronchial infiltrate of inflammatory cells (Figure 2B). This robust influx of leukocytes into the lungs of $\mathrm{HDM}^{+}$Ascaris ${ }^{+}$compared with $\mathrm{HDM}^{-}$Ascaris ${ }^{+}$mice was associated with a significant increase of CCL-11 (eotaxin) (Supplemental Figure 1A; supplemental material available online with this article; https://doi. org/10.1172/JCI127963DS1) and CCL-5 (RANTES) (Supplemental Figure 1B) in the lungs at $5 \mathrm{dpi}$, which continued to be elevated at the peak of larval migration $8 \mathrm{dpi}$. These levels returned to basal levels by 18 dpi. In contrast, CCL-2 (MCP-1) was driven in the Ascaris-infected mice at all 3 time points (Supplemental Figure 1C). Finally, there was no difference in CXCL-5 (LIX) among the groups and time points (Supplemental Figure 1E).

Lung tissue from $\mathrm{HDM}^{+}$Ascaris ${ }^{+}$mice had increased intensity of Alcian blue (AB)/periodic acid-Schiff (PAS) staining at 5 and 8 dpi in comparison with $\mathrm{HDM}^{+}$Ascaris mice (Figure $2 \mathrm{C}$ ), indicating a marked increased of mucus production by the goblet cells in the lung epithelium. In agreement with our $\mathrm{AB} / \mathrm{PAS}$ staining intensity, $\mathrm{HDM}^{+}$Ascaris ${ }^{+}$mice had elevated gene expression of $\mathrm{Muc5a}$ (Figure 2D).

The levels of the major type 2-associated cytokines were measured in lung homogenates, including IL-4 (Figure 2E), IL-13 (Figure 2F), IL-33 (Figure 2G), and IL-5 (Figure 2H), as well as those other cytokines belonging to regulatory and type 1 inflammatory phenotypes (Supplemental Figure 2). Our data demonstrate that allergic sensitization with HDM prior to Ascaris infection induced a markedly significant increase in IL-4, IL-13, and IL-33 levels at day 5 and day 8 in $\mathrm{HDM}^{+}$Ascaris ${ }^{+}$mice compared with $\mathrm{HDM}^{-}$Ascaris ${ }^{+}$ mice. At 8 dpi, $\mathrm{HDM}^{+}$Ascaris ${ }^{+}$mice also had a significant increase in the levels of the regulatory cytokine IL-10 (Supplemental Figure $2 \mathrm{~B}$ ) and the regulatory soluble decoy receptor IL-13R $\alpha 2$ (Supplemental Figure 2C) when compared with $\mathrm{HDM}^{-}$Ascaris ${ }^{+}$mice. Finally, HDM allergic sensitization followed by Ascaris infection also induced an increase of TNF- $\alpha$ levels at day 5 and day 8 (Supplemental Figure 2E), as well as IFN- $\gamma$ levels at day 8 (Supplemen- tal Figure 2F), in comparison with $\mathrm{HDM}^{-}$Ascaris ${ }^{+}$mice. Notably, only Ascaris infection induced a significant increase of IL-4, IL-13, IL-13R $\alpha 2$, IL-1 $\beta$, and TNF- $\alpha$ levels in comparison with naive mice. Interestingly, the IL-5 and IL-6 levels showed a quite different pattern from the IL-4, IL-13, IL-33 in that a marked downregulation of that cytokine occurred at day 8 in $\mathrm{HDM}^{+}$Ascaris ${ }^{+}$compared with only $\mathrm{HDM}^{-}$Ascaris ${ }^{+}$mice.

Allergic sensitization coincident with Ascaris infection drives strong innate and adaptive type 2 immune responses in the lungs associated with an eosinophil- and M2 macrophage-rich environment. The robust inflammatory response induced by the HDM allergic sensitization followed by Ascaris infection was characterized both phenotypically and functionally. Initially, a CD4 ${ }^{+}$ $\mathrm{T}$ cell differentiation-flow cytometry panel was used to assess the nature and frequency of Th1, Th2, and Th17 cells among the lung-purified leukocytes in each group (Figure 3A). Our data demonstrated that at $5 \mathrm{dpi}$, HDM allergic sensitization drove a significant increase in the frequency of IL-5- or IL-13producing $\mathrm{CD}^{+}{ }^{+} \mathrm{T}$ cells (Th2) in $\mathrm{HDM}^{+}$Ascaris ${ }^{-}$mice, as well as in $\mathrm{HDM}^{+}$Ascaris ${ }^{+}$mice, compared with $\mathrm{HDM}^{-}$Ascaris ${ }^{+}$mice and also with the naive $\mathrm{HDM}^{-}$Ascaris ${ }^{-}$mice. The magnitude of Th2 cell differentiation driven by allergic sensitization continued to increase at $8 \mathrm{dpi}$ in $\mathrm{HDM}^{+}$Ascaris mice and in $\mathrm{HDM}^{+}$Ascaris ${ }^{+}$ mice compared with $\mathrm{HDM}^{-}$Ascaris ${ }^{+}$and naive mice. At 8 dpi, the migrating larvae induced an increase of Th2 cells in the lungs of $\mathrm{HDM}^{-}$Ascaris ${ }^{+}$mice compared with naive mice. Finally, at 18 dpi, the frequency of Th2 cells driven by HDM allergic sensitization in the $\mathrm{HDM}^{+}$Ascaris ${ }^{-}$mice progressively decreased, with frequencies near the baseline levels seen in naive mice. At 18 dpi, migrating Ascaris larvae alone drove a marked increase in the frequency of Th2 cells in $\mathrm{HDM}^{-}$Ascaris ${ }^{+}$mice compared with naive animals. However, this robust upregulation of Th2 cells mediated by Ascaris was not as dramatic in $\mathrm{HDM}^{+}$Ascaris ${ }^{+}$mice, suggesting a tolerance to the parasite-induced $\mathrm{Th} 2$ response in HDM-sensitized animals or that the lower parasite burden in the lungs contributed to the attenuated Ascaris-induced $\mathrm{CD}^{+}{ }^{+} \mathrm{T}$ cell response compared with $\mathrm{HDM}^{-}$Ascaris $^{+}$(Figure 3B). Interestingly, the HDM allergic sensitization was associated with a modest increase in IFN- $\gamma$-producing (Th1) and IL-17A-producing (Th17) $\mathrm{CD}^{+}{ }^{+} \mathrm{T}$ cells in the $\mathrm{HDM}^{+}$Ascaris ${ }^{-}$and $\mathrm{HDM}^{+}$Ascaris $^{+}$mice compared with $\mathrm{HDM}^{-}$Ascaris $^{+}$and naive mice at 5 dpi and 8 dpi. At 18 dpi, the frequency of Th1 and Th17 response driven by the allergic inflammation had also returned to baseline. When the pulmonary Th1 and Th17 responses in the $\mathrm{HDM}^{-}$Ascaris ${ }^{+}$mice were evaluated, there were no significant increases in the frequency of IFN- $\gamma$ - or IL-17-producing CD $4^{+} \mathrm{T}$ cells in comparison with naive mice, suggesting that Ascaris infection itself induces a polarized $\mathrm{CD} 4^{+}$Th2 response in the lungs at day 18 (Figure 3, C and D).

To assess the drivers of the augmented Th2-associated lung inflammation, we examined the frequency of innate lymphoid cells (ILCs; CD $45^{+}$Lin $^{-}$CD $4-$ TCR- $\beta$-Thy $1.2^{+}$) and their subsets (by using the expression of the signature cytokines IFN- $\gamma$, IL-5/IL-13, and IL-17A) in the lungs at $8 \mathrm{dpi}$ (Figure 3E). As seen, in the naive mice, the majority of the ILCs were type 1 ILCs (ILC1s) (73\%), with $26 \%$ being ILC2s and $1 \%$ ILC3s. In $\mathrm{HDM}^{-}$Ascaris ${ }^{+}$mice, the subset composition of the ILCs, although increased in frequency, was very similar to that of the naive mice, with $78 \%$ ILC1s, $22 \%$ 

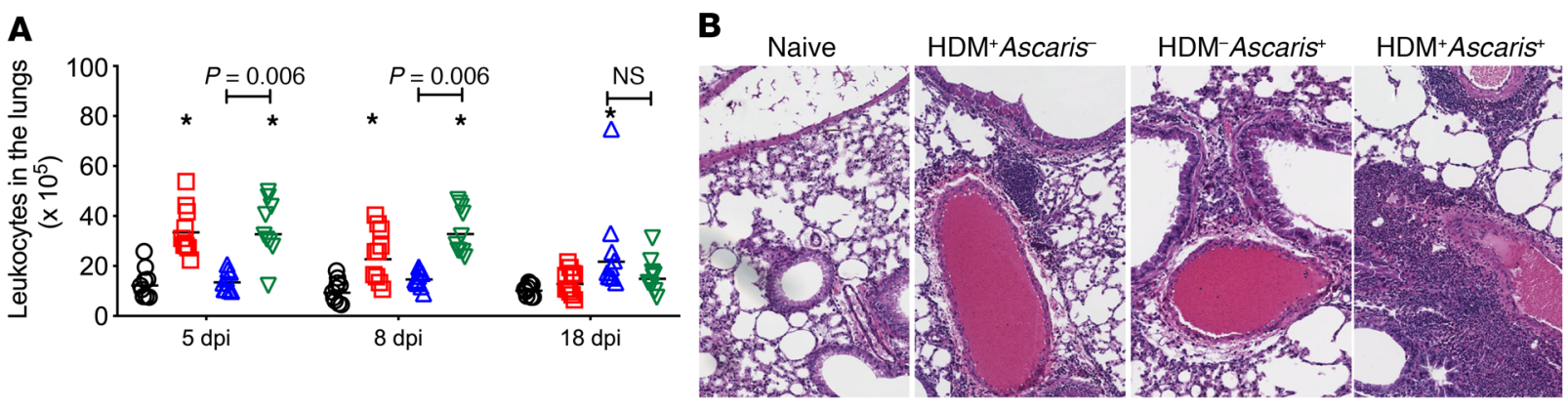

\section{O Naive $\quad \square$ HDM $^{+}$Ascaris $^{-} \quad \Delta$ HDM $^{-}$Ascaris $^{+} \quad \nabla$ HDM $^{+}$Ascaris $^{+}$}

C

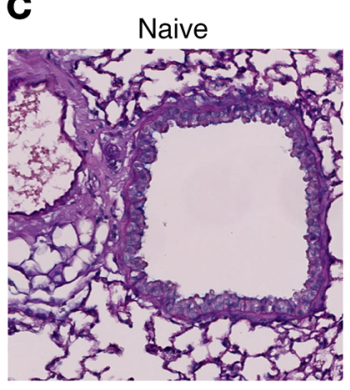

E

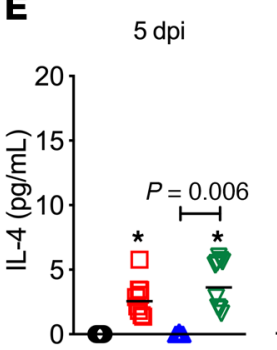

G

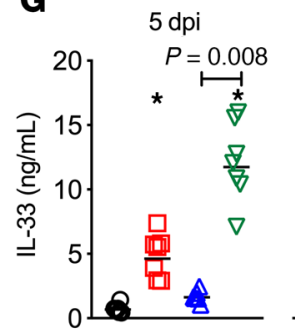

$\mathrm{HDM}^{+}$Ascaris

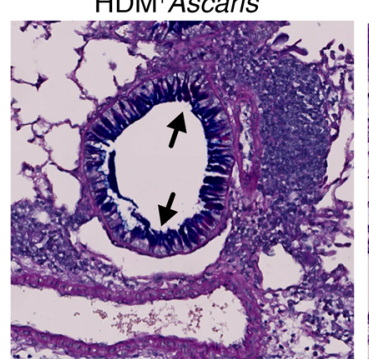

$\mathrm{HDM}^{-}$Ascaris $^{+}$

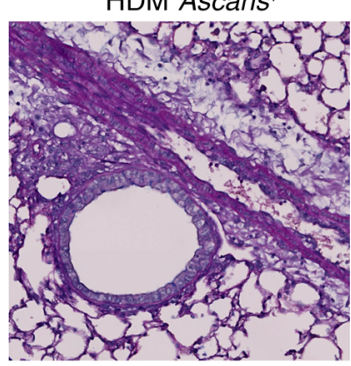

$\mathrm{HDM}^{+}$Ascaris $^{+}$

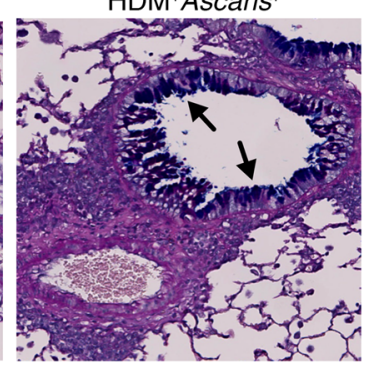

F
$8 \mathrm{dpi} \quad 18 \mathrm{dpi}$

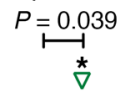

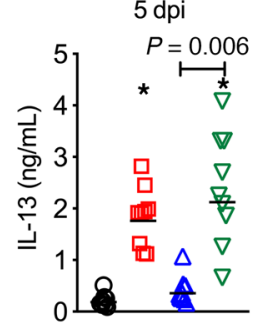

$8 \mathrm{dp}$
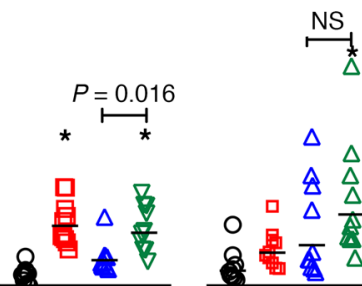

NS
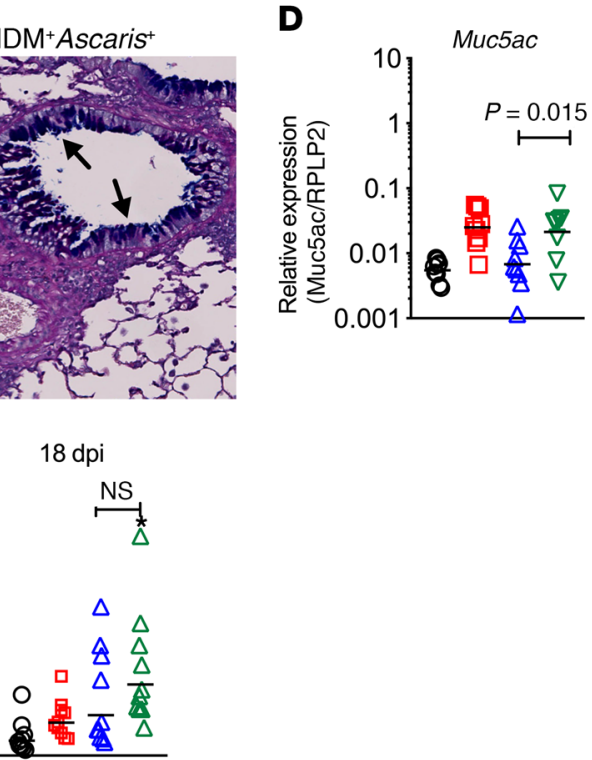

Figure 2. Allergic sensitization followed by Ascaris infection drives a marked influx of inflammatory cells to the lungs, increased mucus production, and a robust type $\mathbf{2}$ immune profile. Cellularity quantification (A), representative H\&E perivascular and peribronchial histological analysis (original magnification, $\times 8$ ) of the inflammatory influx of leukocytes at $8 \mathrm{dpi}(\mathbf{B}), \mathrm{AB} / \mathrm{PAS}$ staining (original magnification, $\times 8$ ) for mucus production by the goblet cells in the lung epithelium (in blue; arrows) at $8 \mathrm{dpi}$ (C), relative gene expression of Muc5ac (D), and pulmonary tissue levels of IL-4 (E), IL-13 (F), IL-33 (C), and IL-5 (H) in the lung's homogenates of naive HDM-Ascaris- (black circles) (a), $\mathrm{HDM}^{+}$Ascaris- (red squares) (b), $\mathrm{HDM}^{-}$Ascaris (blue triangles) (c), and $\mathrm{HDM}^{+}$Ascaris $^{+}$(green triangles) (d) BALB/c mice at day 5 ( $n=9$ mice per group), day 8 ( $n=10$ mice per group), and day 18 ( $n=10$ mice per group). Each symbol represents a single mouse, and the horizontal bars are the GMs. $P$ value is indicated in each graph. Kruskal-Wallis test followed by Dunn's multiple-comparisons test was used for all comparisons; ${ }^{*}$ significantly different $(P<0.05)$ from naive $\left(\mathrm{HDM}^{-}\right.$Ascaris-) group.

ILC2s, and 0\% ILC3s. In contrast, the HDM allergic sensitization followed by Ascaris infection $\left(\mathrm{HDM}^{+}\right.$Ascaris $\left.{ }^{+}\right)$at $8 \mathrm{dpi}$ induced a marked increase in the total number of ILCs with a marked shift in the proportion of ILC subsets with a slight predominance of ILC2s (50\%) compared with ILC1s (49\%) and ILC3s (1\%). Furthermore, at $18 \mathrm{dpi}$, while the HDM-induced ILC2s decreased toward the baseline numbers in the lungs, there was a marked increase in the Ascaris-driven ILC2s $\left(\mathrm{HDM}^{-}\right.$Ascaris $\left.^{+}\right)$. Interestingly, the Ascaris infection in the allergic mice $\left(\mathrm{HDM}^{+}\right.$Ascaris $\left.{ }^{+}\right)$led to lower numbers of ILC2s than in the $\mathrm{HDM}^{-}$Ascaris ${ }^{+}$mice, suggesting either that HDM sensitization downregulated ILC2 expansion/recruitment or that the lower levels of migrating larvae contributed to a lack of ILC2s (Supplemental Figure 3).

The participation and function of granulocytes and myeloid cells in the context of helminth infection with or without a preallergic conditioning were also evaluated (Figure 4). The most marked alteration in the number of lung cells driven by the HDM sensitization was related to the eosinophils (Figure 4A). HDM 
A

○ Naive $\quad \square \mathrm{HDM}^{+}$Ascaris $\quad \triangle \mathrm{HDM}^{-}$Ascaris $^{+} \quad \nabla \mathrm{HDM}^{+}$Ascaris $^{+}$

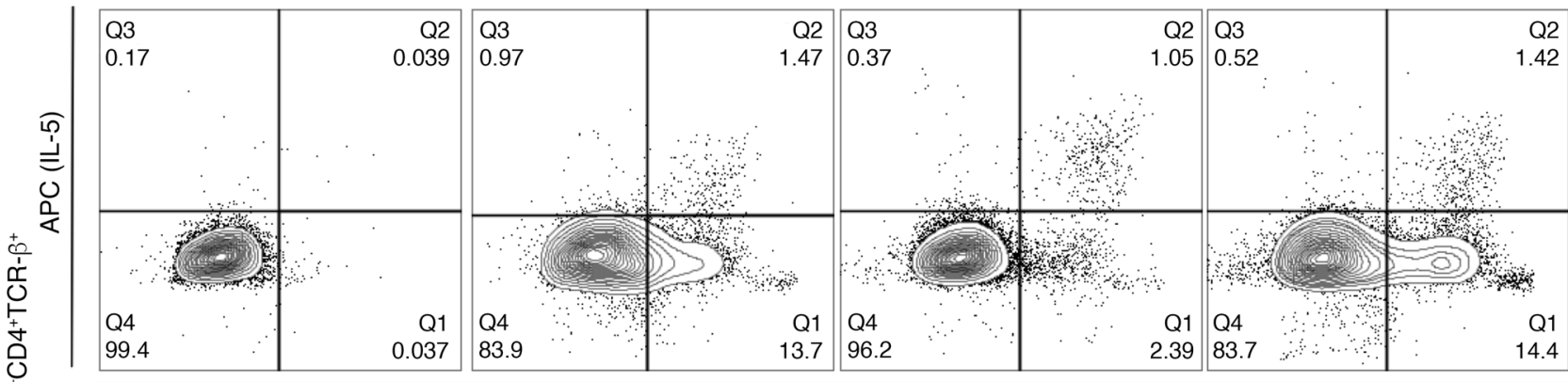

PE (IL-13)

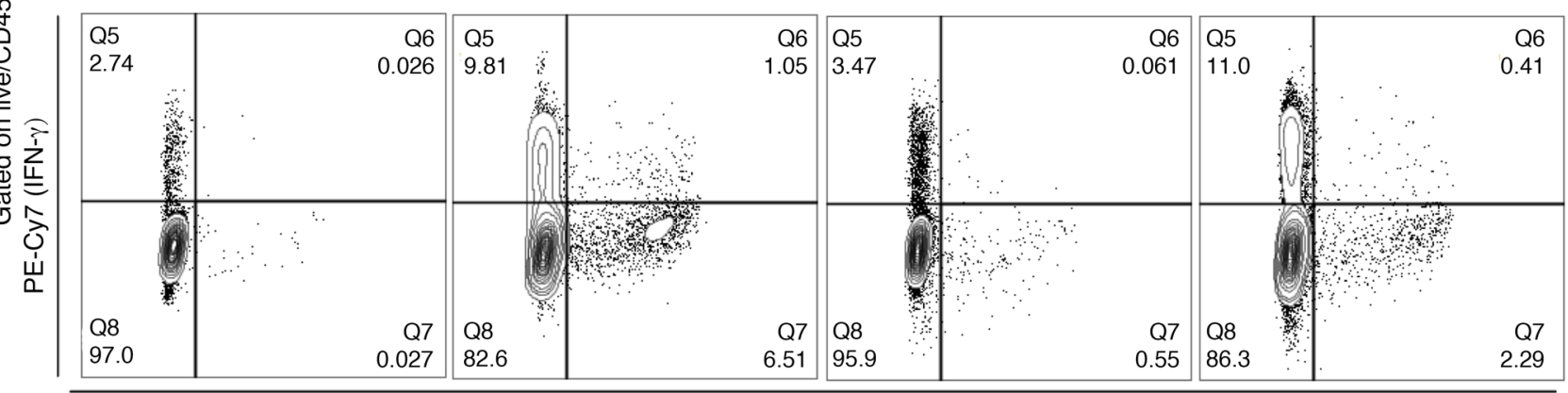

Alexa Fluor 700 (IL-17A)

B

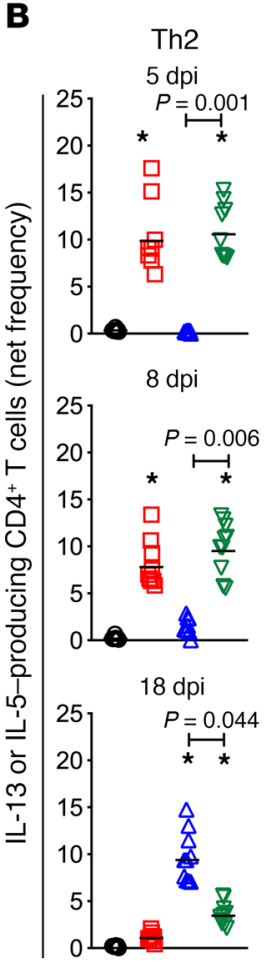

C

Th1

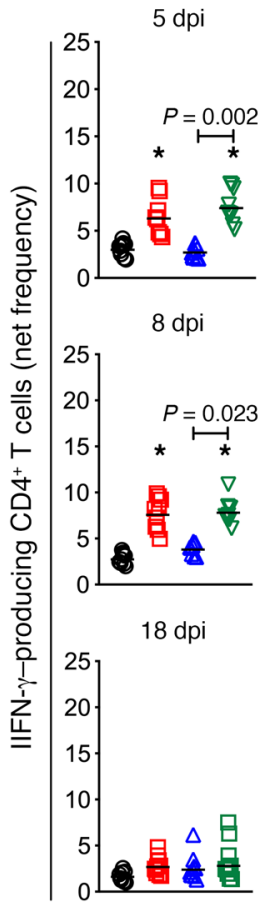

D

Th17
$5 \mathrm{dpi}$
E

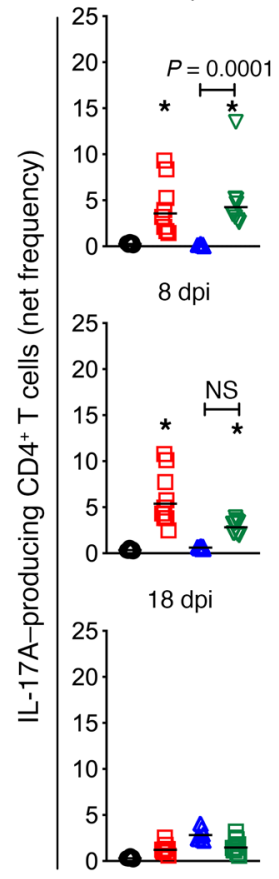

ILCs

Gated on live/CD45+Lin-CD4-TCR- $\beta^{-}$Thy $1.2^{+}$

Figure 3. HDM sensitization followed by Ascaris infection drives a strong innate and adaptive type $\mathbf{2}$ immunity in the lungs. (A) Representative flow cytometry dot plot of lung homogenates, gated on Lin ${ }^{-C D} 45^{+}$TCR- $\beta^{+}$CD4 ${ }^{+}$T cells, showing the frequencies of IL-5 and IL-13 (top) and IFN- $\gamma$ and IL-17 (bottom) in the different groups at day 8. (B-D) The net frequency of IL-5+ or IL-13+ CD4+ Th2 cells (B), IFN- $\gamma^{+}$CD4+ Th1 cells (C), and IL-17A+ CD4 $4^{+}$Th17 cells (D) was assessed at different time points: day 5 ( $n=9$ mice per group), day 8 ( $n=10$ mice per group), and day 18 ( $n=10$ mice per group). Boolean analysis was performed to exclude multifunctional CD4+ $T$ cells expressing IL-5, IL-13, IFN- $\gamma$, and IL-17 simultaneously. (E) Frequency of total innate lymphoid cells (ILCs) gated as CD45+Lin-CD4TCR- $\beta$-Thy.1.2 ${ }^{+}$in the different groups at day 8 of infection, as well as the proportion of ILC1s, ILC2s, and ILC3s, based on the expression of the signature cytokines IFN- $\gamma$, IL-5/IL-13, and IL-17A, respectively, after PMA/ionomycin stimulation. Each symbol represents a single mouse, and the horizontal bars are the $\mathrm{GMs}$. Net frequency of CD4+ $T$ cells was calculated by subtraction of the baseline frequency (nonstimulated) from the frequency following stimulation with PMA/ionomycin. $P$ values are indicated in each graph. Differences were considered statistically significant at $P<0.05$ by Kruskal-Wallis test followed by Dunn's multiple-comparisons test, used for all comparisons; ${ }^{*}$ significantly different $(P<0.05)$ from naive (HDM`Ascaris $)$ group. 
A
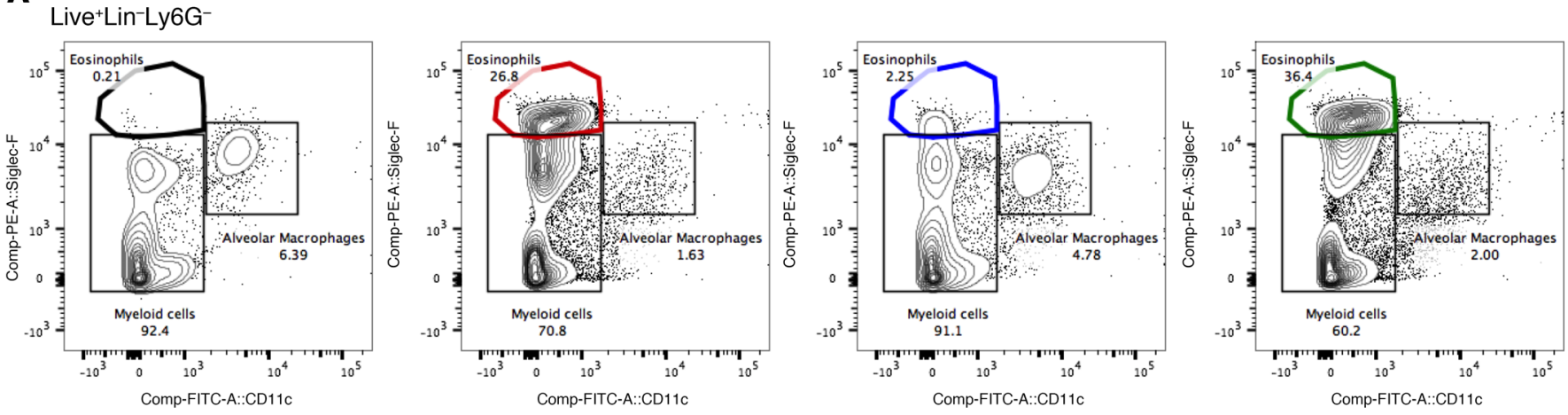

B

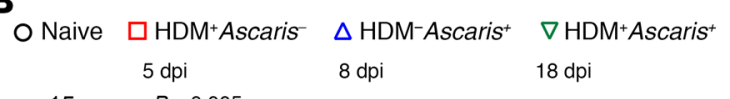

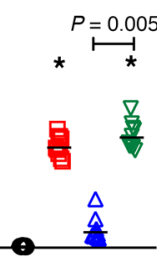

D
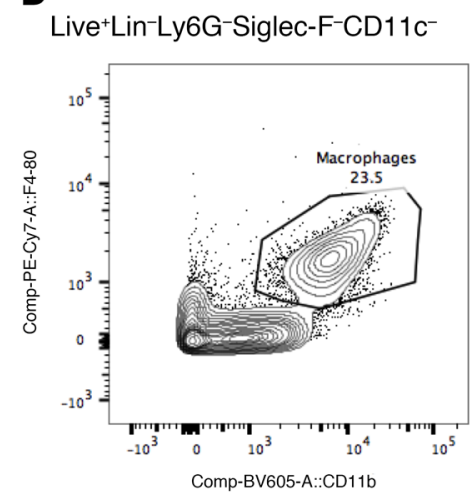

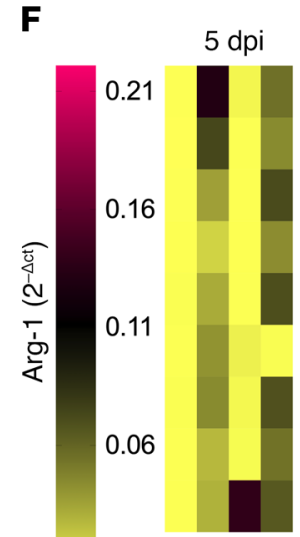

0.01

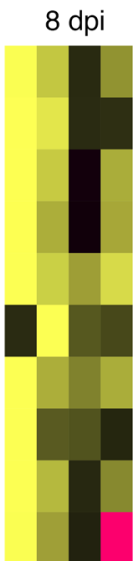

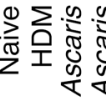

C
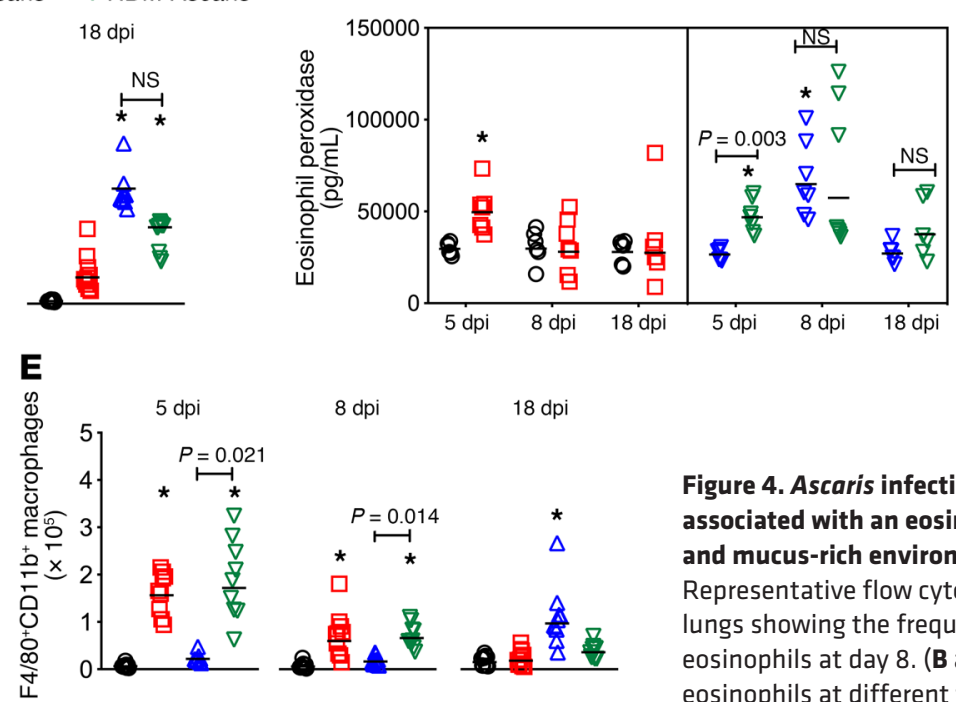

Figure 4. Ascaris infection in preallergic animals is associated with an eosinophil-, M2 macrophage-, and mucus-rich environment in the lungs. (A) Representative flow cytometry dot plots of the lungs showing the frequencies of Siglec $-F^{+} C D 11 c$ eosinophils at day 8. (B and $\mathbf{C}$ ) Absolute number of eosinophils at different time points (B), and eosinophil activation assay by quantification of eosinophil peroxidase (EPO) levels (C). (D) Representative flow cytometry dot plot of the lungs showing the frequencies of $C D 11 b^{+} F 4 / 80^{+}$macrophages at day 8. (E) Absolute number of macrophages at different time points: day 5 ( $n=9$ mice per group), day $8(n=10$ mice per group), and day 18 ( $n=10$ mice per group). (F) Heatmap analysis to compare gene expression of arginase-1 (Arg-1) and iNOS in the lungs of mice from all groups at day 5 ( $n=9$ mice per group) and day $8(n=10$ mice per group). In the heatmap, each row represents the expression level of Arg-1 and iNOS per animal, and the columns represent the different groups. Pink represents highly expressed; yellow means low expression value. Each symbol represents a single mouse, and the horizontal bars are the GMs. $P$ values are indicated in each graph. Differences were considered statistically significant at $P<0.05$ by Kruskal-Wallis test followed by Dunn's multiple-comparisons test, used for all comparisons; ${ }^{*}$ significantly different $(P<0.05)$ from naive (HDM-Ascaris-) group. Wilcoxon matched-pairs test was used for the gene expression analysis between $\mathrm{HDM}^{+}$Ascaris ${ }^{-}$mice and $\mathrm{HDM}^{+}$Ascaris ${ }^{+}$mice. 
allergic sensitization induced a marked influx of Siglec- $\mathrm{F}^{+} \mathrm{C}$ D11 $\mathrm{c}^{-}$eosinophils to the lungs. When compared with naive mice, $\mathrm{HDM}^{+}$Ascaris ${ }^{-}$mice at $5 \mathrm{dpi}$ and at $8 \mathrm{dpi}$ had markedly increased numbers of lung eosinophils. Notably, at 18 dpi (18 days after the last HDM sensitization), the numbers of eosinophils significantly decreased to almost baseline levels. Notwithstanding, in the context of HDM sensitization followed by Ascaris infection, $\mathrm{HDM}^{+}$Ascaris ${ }^{+}$mice showed a robust tissue eosinophilia when compared with $\mathrm{HDM}^{-}$Ascaris ${ }^{+}$mice at 5 dpi. This HDM-induced eosinophilic environment continued to be dominant during the peak of larval migration ( $8 \mathrm{dpi}$ ) in the lungs of $\mathrm{HDM}^{+}$Ascaris ${ }^{+}$mice compared with $\mathrm{HDM}^{-}$Ascaris ${ }^{+}$mice (Figure $4 \mathrm{~B}$ ).

Not only were there increased numbers of eosinophils in the lungs of $\mathrm{HDM}^{+}$Ascaris and $\mathrm{HDM}^{+}$Ascaris ${ }^{+}$mice at $5 \mathrm{dpi}$, but these eosinophils released more of the eosinophil-specific granule protein eosinophil peroxidase (EPO), suggesting these eosinophils were activated and showed evidence of degranulation in the tissue. Interestingly, at $8 \mathrm{dpi}$, both $\mathrm{HDM}^{-}$Ascaris $^{+}$mice and $\mathrm{HDM}^{+}$Ascaris ${ }^{+}$ mice had increased EPO levels when compared with $\mathrm{HDM}^{+}$Ascaris and naive mice. Finally, at 18 dpi, all groups had EPO levels similar to homeostatic levels seen in naive, $\mathrm{HDM}^{+}$Ascaris, $\mathrm{HDM}^{-}$Ascaris ${ }^{+}$, and $\mathrm{HDM}^{+}$Ascaris ${ }^{+}$mice (Figure $4 \mathrm{C}$ ). No relevant differences were observed among the groups and time points in the numbers of Ly $6 \mathrm{G}^{+}$neutrophils.

We next evaluated the number of $\mathrm{F} 4 / 80^{+} \mathrm{CD} 11 \mathrm{~b}^{+}$macrophages in the lung tissue of the animals, and we observed a pattern similar to that seen for the eosinophils (Figure 4, D and E). HDM allergic sensitization induced a marked increase of macrophages in the lungs of $\mathrm{HDM}^{+}$Ascaris ${ }^{-}$mice as well as $\mathrm{HDM}^{+}$Ascaris $^{+}$mice at $5 \mathrm{dpi}$ and $8 \mathrm{dpi}$, returning to baseline levels at $18 \mathrm{dpi}$. Interestingly, in parallel to what was seen for the eosinophils, in $\mathrm{HDM}^{-}$Ascaris ${ }^{+}$mice, there was a marked increase in the number of these macrophages from day 5 to day 18 post-infection, in comparison with naive mice.

Analysis in the lung tissue using markers of M1 (iNOS) and M2 (arginase-1 [Arg-1]) macrophages by quantitative PCR revealed that the $\mathrm{HDM}$ allergic sensitization in $\mathrm{HDM}^{+}$Ascaris and $\mathrm{HDM}^{+}$Ascaris ${ }^{+}$mice drove the lung macrophages toward the M2 phenotype (17.6-fold change in Arg-1) in comparison with $\mathrm{HDM}^{-}$Ascaris $^{+}$mice at $5 \mathrm{dpi}$. These data suggest that when the first group of Ascaris larvae reached the lung tissue of HDMsensitized mice at $5 \mathrm{dpi}$, there was already present an M2 macrophage-rich environment not seen in $\mathrm{HDM}^{-}$Ascaris ${ }^{+}$mice. At $8 \mathrm{dpi}$, the Ascaris infection by itself also induced a significant increase of Arg-1 expression, suggesting that the primary migration of helminth larvae in the lungs is also associated with an increase in M2 macrophages (Figure 4F). No relevant differences were observed among the groups in macrophage differentiation at $18 \mathrm{dpi}$.

Ascaris migration and development occur normally in the absence of eosinophils in allergic animals. Eosinophils are critical to both allergic inflammation and host resistance to some helminth infections. Having identified an expansion of eosinophils in the lung tissue of $\mathrm{HDM}^{+}$Ascaris ${ }^{+}$mice, we hypothesized that the influx of eosinophils in mice with HDM sensitization was impairing the migration and development of Ascaris larvae. To test this, we sensitized eosinophil-deficient mice ( $\triangle$ dblGATA) with HDM before Ascaris infection (Figure 5A). As expected, $\mathrm{HDM}^{+}$Ascaris ${ }^{+}$WT mice had a marked increase in the frequency of Siglec- $\mathrm{F}^{+} \mathrm{CD} 11 \mathrm{c}^{-}$eosinophils in the lung, while eosinophils were absent in $\mathrm{HDM}^{+}$Ascaris ${ }^{+} \Delta$ dblGATA mice (Figure 5B). HDM sensitization in WT mice decreased the number of larvae in the lung tissue and BAL in comparison with HDMunsensitized Ascaris-infected WT mice, as seen previously (Figure 1). Strikingly, allergic sensitization in eosinophil-deficient mice had no impact on the larval migration (Figure 5C). In parallel with our migration findings, Ascaris development occurred normally in the absence of eosinophils, regardless of whether or not mice were sensitized with HDM (Figure 5D). These findings suggest that eosinophils are the cell type that impairs Ascaris development in allergic sensitized mice. Finally, the immune response of HDMinduced allergy and concomitant Ascaris infection in the absence of eosinophils was also evaluated. The quantification of type 2 cytokines in the lung's homogenate demonstrated that in the absence of eosinophils there was a marked reduction in the levels of IL-4 from $\mathrm{HDM}^{+}$Ascaris ${ }^{+}$eosinophil-deficient mice compared with $\mathrm{HDM}^{+}$Ascaris $^{+}$WT mice, although there was no difference in the levels of IL-13 nor IL-33, which remained elevated in the 2 mouse strains (Figure 5F). The increase in the frequency of HDM-induced $\mathrm{CD}^{+}$Th2 cells in the lungs of $\mathrm{HDM}^{+}$Ascaris ${ }^{+}$mice was not affected by the absence of eosinophils (Figure $5 \mathrm{G}$ ), nor were there differences in the number of M2 macrophages (Figure $5 \mathrm{H}$ ) or in mucus production (Figure 5I).

HDM-induced immunity to Ascaris parasites is dependent on eosinophils driven by $\mathrm{CD}^{+} \mathrm{T}$ cells. After showing that HDMinduced larval arrest was related to the presence of eosinophils in the lungs, we sought to determine whether the HDM-induced eosinophil-mediated effect on Ascaris larval development was dependent on $\mathrm{CD}^{+} \mathrm{T}$ cells. Thus, $\mathrm{CD}^{+} \mathrm{T}$ cells were depleted in $\mathrm{HDM}^{+}$Ascaris ${ }^{+}$mice either before HDM allergic sensitization (day 0) or after HDM sensitization (day 18) (Figure 6). As can be seen, only the in vivo administration of anti-CD4 neutralizing antibodies prior to and during the HDM allergic sensitization (day 0) significantly impaired the HDM-induced reduction in larval numbers (and developmental arrest) (Figure 6, B-D), as neutralizing CD4 ${ }^{+} \mathrm{T}$ cells following HDM allergic sensitization had little or no effect on larval numbers or development.

Moreover, the in vivo administration of CD4 neutralizing antibodies prior to the HDM allergic sensitization significantly reduced the frequency and numbers of eosinophils in the lungs (a reduction similar to that of the numbers found in nonallergic animals) and also diminished the HDM-specific IgE and IgG1 antibody levels. These data suggest that the type 2-dominant HDM-induced effect on Ascaris parasites is dependent on eosinophils driven by $\mathrm{CD} 4^{+} \mathrm{T}$ cells (Figure $6 \mathrm{E}$ ).

Delayed infection in HDM-sensitized mice prevents migration. While it is likely that humans would be sensitized to HDM early in life but infected with a helminth well after HDM exposure, we next investigated whether allergic inflammation still limited parasite infection after a delay. WT mice were sensitized with HDM and then, 20 days later, were challenged with HDM and then infected with Ascaris (Figure 7A). As noted previously, 20 days after the last intranasal sensitization with HDM, the frequency of eosinophils, M2 macrophages, and Th2 cells and cytokine and chemokine levels have already returned to baseline. Thus, we evaluated the parasite burden and lung-specific immune response in $\mathrm{HDM}^{-}$Ascaris ${ }^{+}$and $\mathrm{HDM}^{+}$Ascaris ${ }^{+}$groups. As seen previously, at 8 dpi the total burden 
A
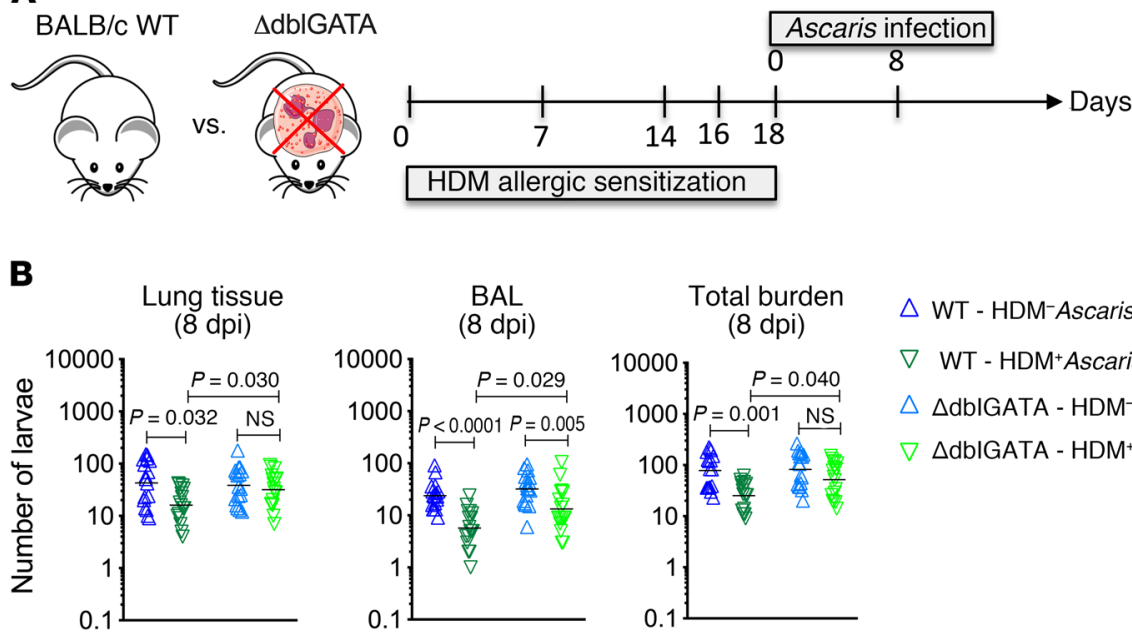

$\triangle \mathrm{WT}$ - $\mathrm{HDM}^{-}$Ascaris $^{+}$

$\nabla{\text { WT }-\mathrm{HDM}^{+} \text {Ascaris }}^{+}$

$\triangle \triangle$ dbIGATA - HDM ${ }^{-}$Ascaris $^{+}$

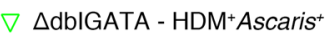

C
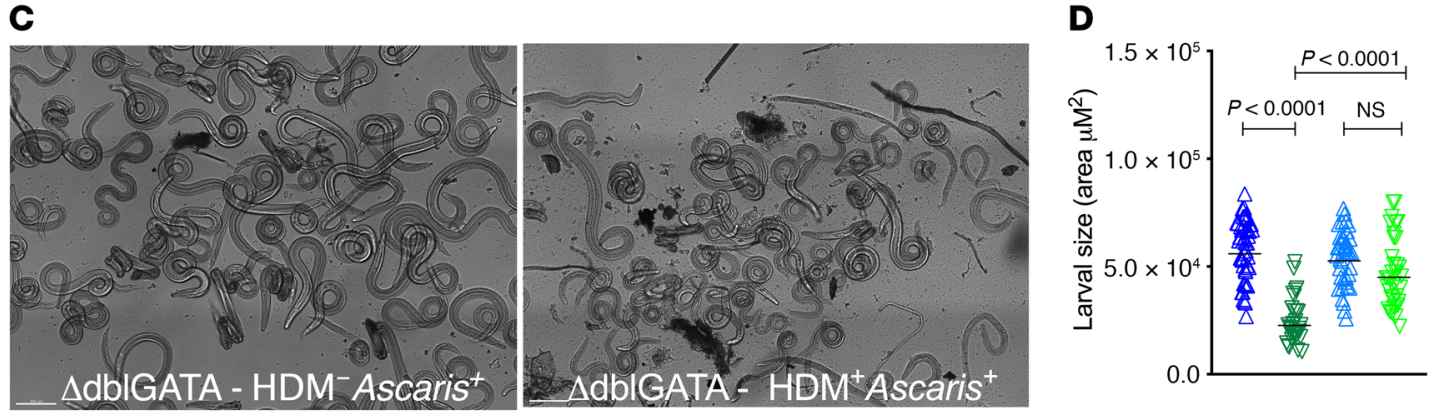

E

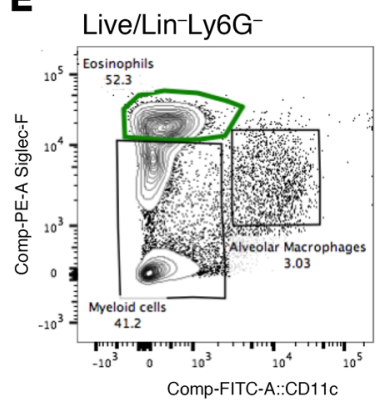

$\mathrm{BALB} / \mathrm{C}$ WT - Allergy ${ }^{+}$Ascaris

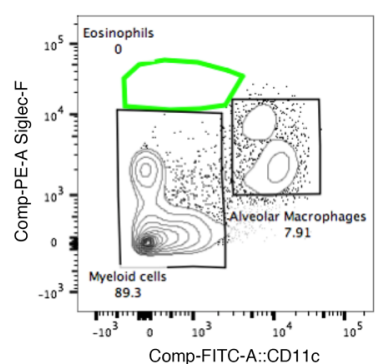

$\triangle \mathrm{dbIGATA}-$ Allergy $^{+}$Ascaris $^{+}$

G

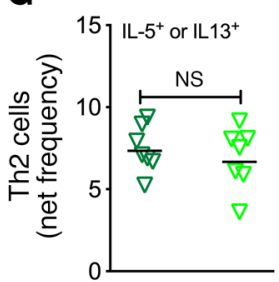

H
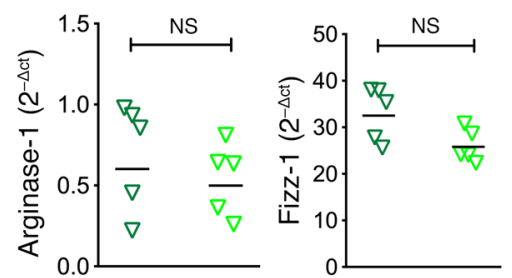

I

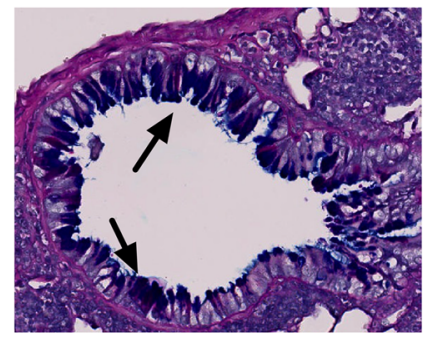

$\nabla \mathrm{WT}\left(\mathrm{HDM}^{+}\right.$Ascaris $)$
$\mathbf{F}$
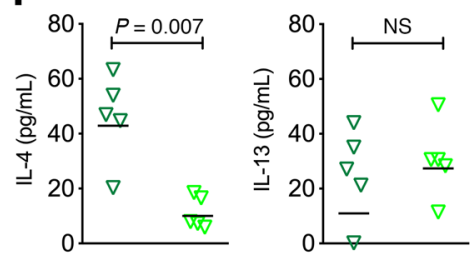

Figure 5. Ascaris larval migration and development occur normally in allergic eosinophil-deficient mice. (A) Experimental design scheme for HDM allergic sensitization followed by Ascaris infection in WT BALB/c and eosinophil-knockout mice ( $\triangle \mathrm{dblCATA}$ ). (B-D) Total parasite burden in the lungs and BAL at day 8 of infection ( $n=17$ mice per group) (B), as well as a representative bright confocal image of lung-stage larvae recovered from Ascaris-infected $\triangle$ dbICATA mice following or not following HDM allergic sensitization (HDM-Ascaris ${ }^{+}$vs. $\mathrm{HDM}^{+}$Ascaris ${ }^{+}$) (scale bars: $200 \mu \mathrm{m}$ ) (C) and a morphometric analysis of these larvae recovered (D). Three independent experiments were performed. (E-I) Characterization of the lung-specific immune response of $\mathrm{HDM}^{+}$Ascaris ${ }^{+}$WT ( $n=5$ mice) (dark green triangles) and $\mathrm{HDM}^{+}$Ascaris $^{+} \Delta$ dblGATA mice ( $n=5$ mice) (light green triangles) by flow cytometry phenotypic analysis, cytokine production, M2 macrophage marker gene expression, and histology of lung epithelium. (E) Eosinophils. (F) IL-4, IL-13, and IL-33 cytokine quantification. (G) IL-5- or IL-13producing $\mathrm{CD}^{+}{ }^{+}$Th2 cell frequency ( $n=7$ mice per group). (H) Arginase- 1 and Fizz-1 gene expression in the lungs. (I) Lung sections stained by AB/PAS showing mucus production by the goblet cells in the lung epithelium (in blue; arrows) (original magnification, $\times 16$ ). Each symbol represents a single mouse, and the horizontal bars are the GMs. $P$ values are indicated in each graph. Differences between $\mathrm{HDM}^{+}$Ascaris $^{+}$(WT) and $\mathrm{HDM}^{+}$Ascaris ${ }^{+}$(GATA) mice were considered statistically significant at $P<0.05$ by unpaired Mann-Whitney test. *Significantly different $(P<0.05)$ from naive (HDM-Ascaris $\left.{ }^{-}\right)$group. Kruskal-Wallis test followed by Dunn's multiple-comparisons test was used to compare WT $\mathrm{HDM}^{+}$Ascaris $^{+}$versus $\triangle$ dblGATA HDM ${ }^{+}$Ascaris $^{+}$in $\mathbf{B}$ and $\mathbf{D}$. 
in the lungs (tissue $+\mathrm{BAL}$ ) showed a marked approximately $68 \%$ reduction in the number of larvae in $\mathrm{HDM}^{+}$Ascaris ${ }^{+}$mice compared with $\mathrm{HDM}^{-}$Ascaris ${ }^{+}$mice. Surprisingly, the $\mathrm{HDM}^{+}$Ascaris ${ }^{+}$ (20 days) mice also showed a marked approximately $45 \%$ reduction in the parasite burden when compared with $\mathrm{HDM}^{-}$Ascaris ${ }^{+}$ mice (Figure 7B). The immunophenotyping of inflammatory cell subsets in the lungs demonstrated that, although of lower magnitude than observed in $\mathrm{HDM}^{+}$Ascaris ${ }^{+}$mice following the standard sensitization protocol, Ascaris infection 20 days after HDM sensitization induced an increase in the absolute number of eosinophils (Figure 7C), and the frequency of Th2 cells (Figure 7D), in comparison with $\mathrm{HDM}^{-}$Ascaris ${ }^{+}$mice. Interestingly, no differences were observed in the IL-4 levels in the lung homogenates of $\mathrm{HDM}^{+}$Ascaris $^{+}$(20 days) mice compared with $\mathrm{HDM}^{-}$Ascaris ${ }^{+}$ mice (Figure 7E). There was, however, a marked increase in IL-13 and IL-13R $\alpha 2$ levels in $\mathrm{HDM}^{+}$Ascaris ${ }^{+}$mice compared with $\mathrm{HDM}^{-}$Ascaris $^{+}$animals (Figure 7, F and $\mathrm{G}$ ), highlighting a potential role for IL-13 signaling as a secondary mechanism of HDMinduced protective immunity to helminths.

\section{Discussion}

Allergic diseases and helminth infections are 2 distinct and relatively nonoverlapping geographical public health concerns (45) that together affect more than 3 billion people $(46,47)$. However, globalization and its extensive population movement have resulted in the intersection of these once separate public health problems.

Our study takes a novel look at the relationship between helminth infection and allergic sensitization/disease by examining the influence of preexisting allergic sensitization on the outcome of helminth infections, rather than the more traditional approach of examining the converse (48). As has been studied quite extensively, chronic helminth infection has been associated with diminished allergic reactivity. As reviewed by many $(23,49,50)$, among the various hypotheses to explain the modulatory influence of helminth infection on allergy, the IL-10-induced suppression of Th2 effector responses $(51,52)$ and/or the expansion of natural and parasite-induced regulatory $\mathrm{T}$ cells (Tregs) have been the leading candidates $(26,53,54)$. Nevertheless, "allergic-like symptoms" have been associated with relatively acute helminth infections (e.g., urticaria in many helminth infections, angioedema in filarial infections, asthma in slaughterhouse workers exposed to Ascaris, swimmer's itch in schistosomiasis). In this way, understanding whether allergic inflammation can regulate helminth parasite intensity and development in their early migration phase provides a new perspective for this interaction. The present study provides a window on the mechanisms underlying tissue-specific responses that can drive a protective response against the early stages of the helminth parasites prior to their establishing long-lasting infections in the host.

Here we used a murine model of HDM-induced allergic pulmonary inflammation followed by Ascaris infection to demonstrate that allergic sensitization to environmental aeroallergens (e.g., HDM) in the context of a subsequent helminth infection drives an eosinophil-rich pulmonary type 2 response that directly hinders larval development and markedly reduces parasite burden. This effect is dependent on the presence of eosinophils, as eosinophil-deficient mice were unable to limit parasite development or numbers. In the present study, we have carefully dissected the immunobiology of larval ascariasis in the lungs of naive mice and compared it with the course of the infection in mice with preexisting allergic asthma. By using different time points of investigation, we have demonstrated that during primary exposure to Ascaris, the larvae in the lungs elicit a strong innate tissue response characterized by increased levels of IL-4, IL-5, IL-6, and IL-33 cytokines as well as marked increases in the chemokines CCL-11 (eotaxin), CCL-2 (MCP-1), and CXCL-10 (IP-10). Moreover, there is a small but measurable accumulation of $\mathrm{CD}^{+}$effector Th2 cells, activated eosinophils, and alternatively activated macrophages (M2). Despite this type 2-associated inflammation, the environment still allows lungstage Ascaris larvae to develop in the tissue, increasing considerably in length and width, and to reach the airways while causing significant hemorrhage and tissue damage. If, however, there is HDM sensitization prior to infection with Ascaris, there is an even more profound type 2 inflammation characterized initially by even more elevated levels of CCL-11, CCL-5, IL-25, and IL-33 followed by an increase in both IL-5/IL-13-producing ILC2s and CD $4^{+}$Th 2 cells.

It has been shown previously that during HDM sensitization airway epithelial cells can sense allergens (e.g., HDM) through Toll-like receptor 4 (TLR4) (55), which in turn leads to the release of chemokines, cytokines, and signals, including thymic stromal lymphopoietin (TSLP), granulocyte-macrophage colonystimulating factor (GM-CSF), IL-25, and IL-33, that can activate and recruit other immune effector cells to the site of inflammation (56). This process can trigger the differentiation of naive $\mathrm{T}$ cells into adaptive $\mathrm{CD} 4^{+} \mathrm{Th} 2$ cells, induce eosinophilic inflammation, polarize toward M2 macrophages, and drive mucus production and airway hyperresponsiveness (57-59). In the present study, the HDM allergen-driven inflammation following Ascaris infection induces an IL-33-driven inflammatory milieu with dramatic increases of activated eosinophils, differentiation of lung macrophages toward the M2 phenotype, and an IL-4- and IL-13-rich environment associated with mucus production by goblet cells in the epithelium (Figure 8).

IL-13 is a pleiotropic cytokine predominantly produced by Th2 cells that mediates its effects through the IL-13R $\alpha 1 / \mathrm{IL}-4 \mathrm{R} \alpha$ heterodimer to induce genes specific to Th2 inflammation (60). This Th2-associated response has been shown to lead to a protective response to certain helminth parasites (60) but, at the same time, can play an important role in the pathogenesis of asthma (61). It has been shown that IL-13 signaling through IL-13R $\alpha 1$ induces the upregulation of IL-13R $\alpha 2$ decoy receptor (62), which serves to downregulate/limit the IL-13-mediated responses in vivo (63-65). In fact, HDM allergic sensitization followed by Ascaris infection markedly upregulated levels of both IL-13 and IL-13R $\alpha 2$ at 8 dpi when compared with Ascaris infection alone. Moreover, the high expression of both IL-13 and IL-13R $\alpha 2$ was also associated with the eosinophil-dominated type 2 response in the last protective phenotype in the allergic animals with a 20-day delay before infection with the helminth. These findings suggest a potential role for the regulation of the IL-13/IL-13R $\alpha 2$ axis in the helminth-protective lung-specific responses induced by the allergic sensitization. 
A

Group day $0 \quad \begin{gathered}\text { Anti-CD4 GK1.5 } \\ \text { or } \\ \text { IgG2b isotype control }\end{gathered}$

Group day 18

CD4 depletion before allergic sensitization and infection

CD4 depletion after allergic sensitization and before infection

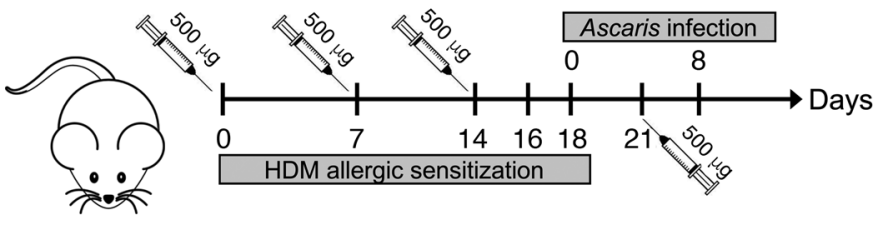

B

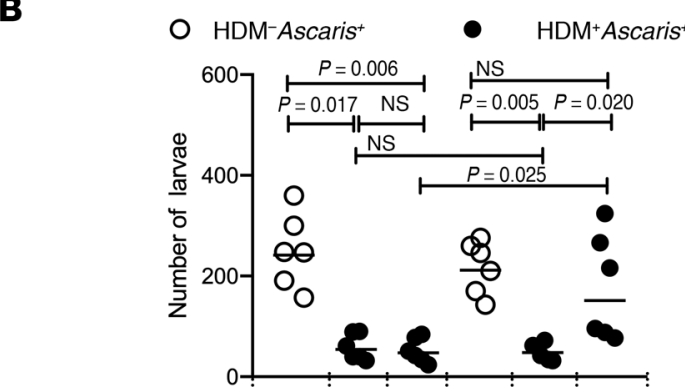

IgG isotype ctrl (day 0)

Anti-CD4 (day 0)

IgG isotype ctrl (day 18)

Anti-CD4 (day 18)

D

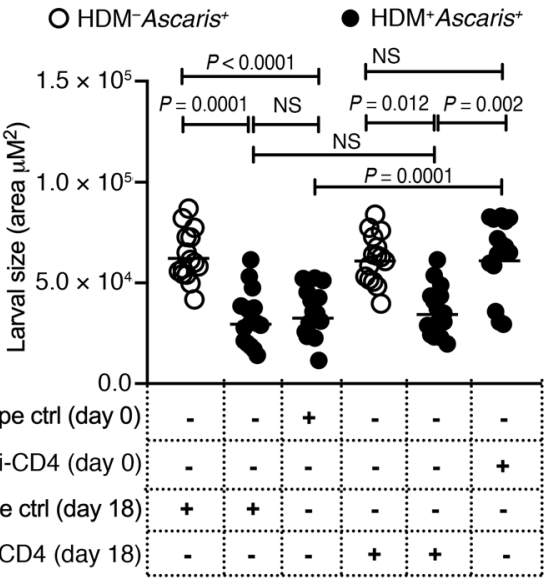

E

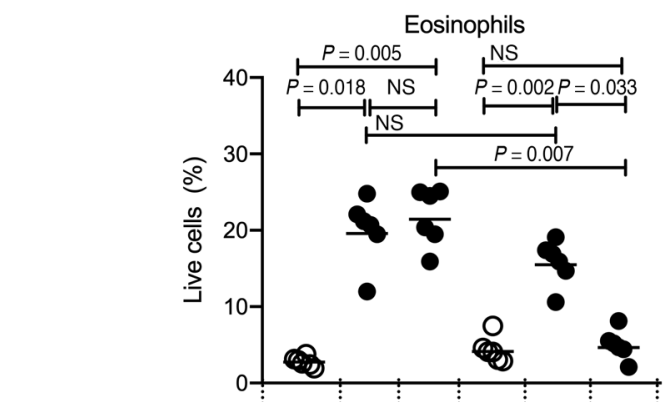

IgG isotype ctrl (day 0)

Anti-CD4 (day 0)

IgG isotype ctrl (day 18)

Anti-CD4 (day 18)
C

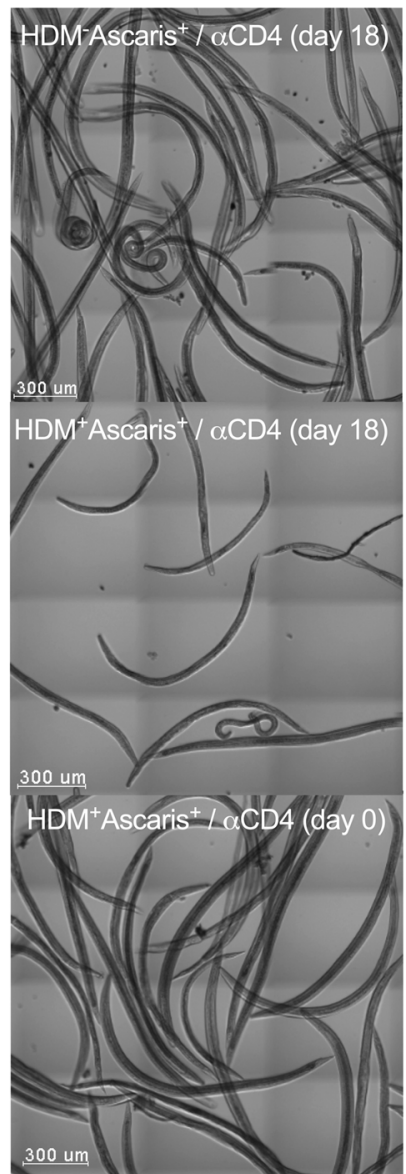

Figure 6. HDM-induced immunity to Ascaris parasites is dependent on eosinophils driven by $\mathrm{CD4}^{+} \mathrm{T}$ cells. (A) Experimental design scheme for $\mathrm{CD}^{+} \mathrm{T}$ cell depletion in unsensitized mice followed by Ascaris infection: $\mathrm{HDM}^{-}$Ascaris $^{+}$ (open circles in B, D, and E) and HDM-sensitized Ascaris-infected (filled circles in $\mathbf{B}, \mathbf{D}$, and $\mathbf{E}$ ) mice received anti-CD4 antibodies before and continuously during the HDM sensitization at days $0,7,14$, and 21 (group day 0 ), or after allergic sensitization at days 18 and 25 (group day 18) ( $n$ = 6 mice per group). Rat IgG2b antibody was used as the isotype control. (B) Total parasite burden in the BAL at $8 \mathrm{dpi}$. (C) Representative bright confocal images of the larvae recovered in the BAL at 8 dpi (scale bars: $300 \mu \mathrm{m}$ ). (D) Lung-stage larval development by morphometric analysis of larva size recovered from $\mathrm{HDM}^{-}$Ascaris ${ }^{+}$and $\mathrm{HDM}^{+}$Ascaris ${ }^{+}$treated with anti-CD4 or isotype control. (E) Characterization of the lung-specific immune response by flow cytometry, showing the frequency of Siglec- $\mathrm{F}^{+} \mathrm{CD} 11 \mathrm{c}^{-}$eosinophils and serum HDM-specific IgE and IgG1 antibody levels. Each symbol represents a single mouse, and the horizontal bars are the GMs. $P$ values are indicated in each graph. Nonparametric Kruskal-Wallis test followed by Dunn's multiple-comparisons test was used for differences among the isotype control-treated groups and anti-CD4-treated groups, and the differences for $\mathrm{HDM}^{+}$Ascaris $^{+}$ animals treated with lgG2b or anti-CD4 antibodies were considered statistically significant at $P<$ 0.05 by Kruskal-Wallis test followed by Dunn's multiple-comparisons test.
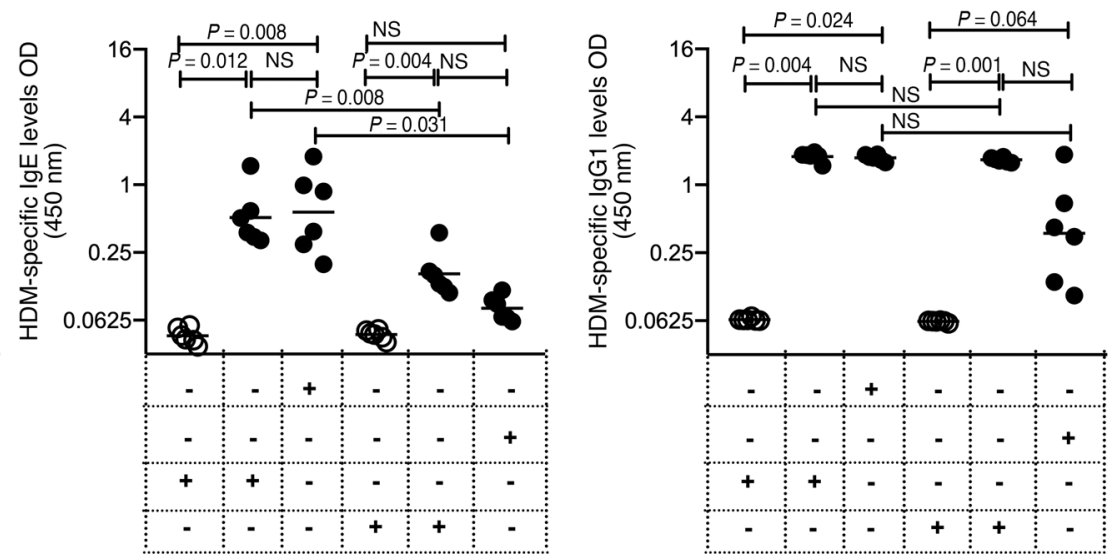
A

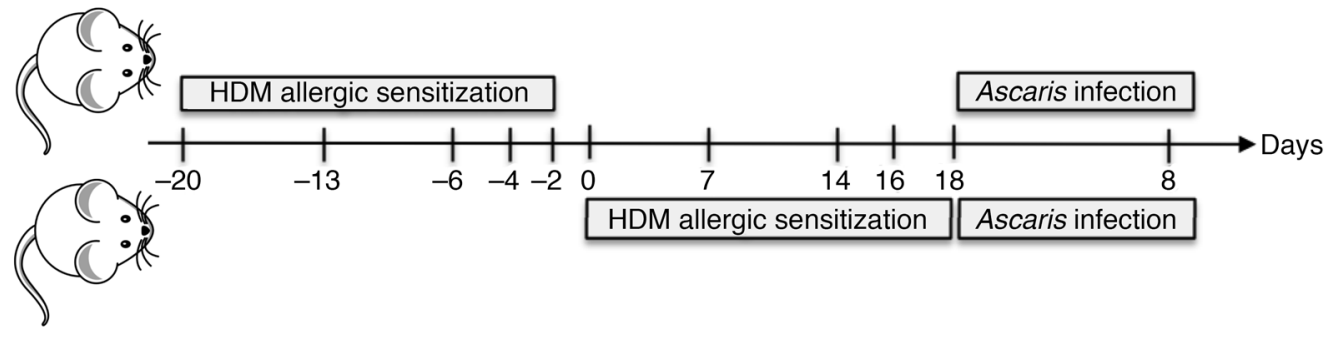

$\triangle \mathrm{HDM}^{-}$Ascaris $^{+}$

C

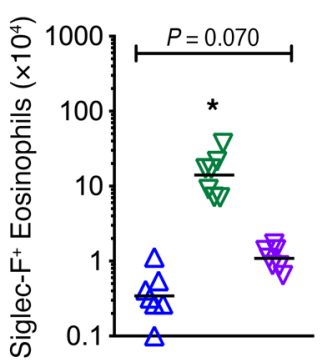

$\nabla \mathrm{HDM}^{+}$Ascaris $^{+}$

\section{D}

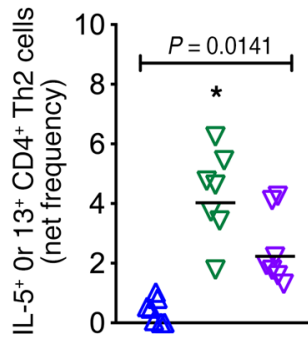

$\nabla \mathrm{HDM}^{+}$Ascaris $^{+}$(20 days)

E

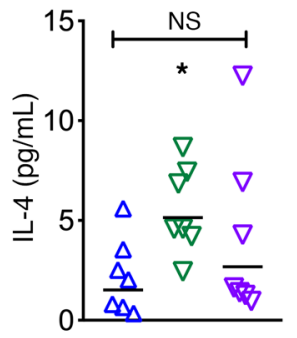

B

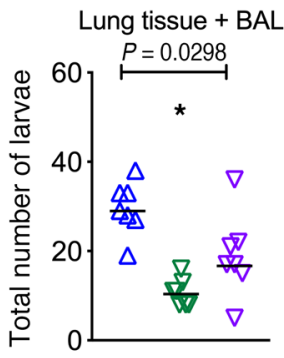

$\mathbf{F}$

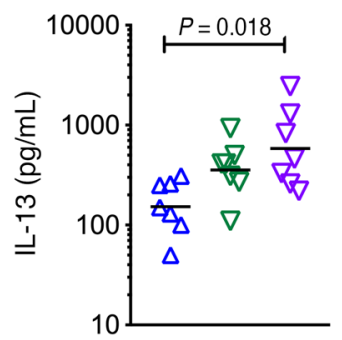

G

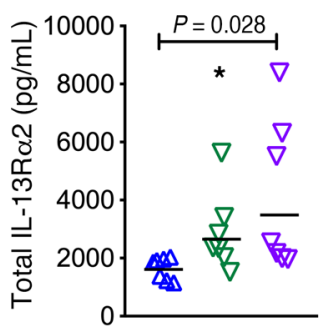

Figure 7. HDM allergic sensitization induces a persistent protective type $\mathbf{2}$ immunity followed by later Ascaris infection. (A) Experimental design scheme for unsensitized mice followed by Ascaris infection, $\mathrm{HDM}^{-}$Ascaris ${ }^{+}$(blue triangles) ( $n=7$ mice); and HDM allergic sensitization followed by Ascaris infection at 2 different time points: $\mathrm{HDM}^{+}$Ascaris $^{+}$(green triangles) ( $n=7$ mice), infected right after the last sensitization with $\mathrm{HDM}$, and $\mathrm{HDM}^{+}$Ascaris ${ }^{+}$ (20 days) (purple triangles) ( $n=7$ mice), infected 20 days after the last sensitization with HDM. (B) Total parasite burden in the lung tissue and BAL at day 8 of infection. (C and $\mathbf{D})$ Characterization of the lung-specific immune response by flow cytometry, showing eosinophils (C) and IL- $-5^{+}$or IL-13+ $C D 4^{+}$Th2 cell frequency (D). (E-C) IL-4, IL-13, and IL-13Ra2 levels quantified in the lung homogenates of each group. Each symbol represents a single mouse, and the horizontal bars are the GMs. $P$ values are indicated in each graph. Kruskal-Wallis test followed by Dunn's multiple-comparisons analysis was used for differences among the groups; * significantly different $(P<0.05)$ from HDM`Ascaris ${ }^{+}$group by the same analyses.

Although the mechanisms of helminth killing in the tissue prior to adult worm expulsion remain largely unstudied, studies using the rodent helminth parasites Nippostrongylus brasiliensis and Heligmosomoides polygyrus have identified some important mediators associated with the control of the larval migration in the tissue. However, these have typically been seen in the context of secondary infections after the initial infection had been cleared. It may be, therefore, that the HDM sensitization mirrors a primary helminth infection such that the Ascaris infection (following HDM sensitization) initiates the kind of response that clearly controls larval tissue penetration and development. It is clear that the extraordinarily robust lung-specific response results in larval developmental arrest (and a 70\% reduction in the parasite burden), a process that appears largely to be mediated by eosinophils.

Although eosinophilia is a hallmark of tissue-invasive helminth infections (37), the role of these cells in controlling the infection is unclear. The capacity of eosinophils to kill helminth nematodes has been extensively studied using in vitro assays and in vivo models. O'Connell et al. (66) suggested that eosinophils can kill Strongyloides stercoralis larvae through an eosinophil granule protein-dependent mechanism if other effector cells are absent. Moreover, it has been shown that eosinophil granule proteins are toxic to microfilariae of Brugia parasites in vitro (67). Recently, it has been shown that $H$. polygyrus intestinal infection led to a significant increase in immune-mediated killing of $N$. brasiliensis larvae within the lung of coinfected mice. This enhanced protection was associated with IL-33-mediated activation of $\mathrm{CD}^{+}{ }^{+} \mathrm{Th} 2$ cells, which orchestrated IL-5-mediated eosinophil-dependent larval killing (68). In addition, our results suggest that HDMinduced reduction in Ascaris numbers and arrested development is dependent on eosinophils in the lungs driven by $\mathrm{CD} 4^{+} \mathrm{T}$ cells (see Figure 6). However, our data also demonstrate that once a type 2 allergic environment is established, the $\mathrm{CD} 4^{+} \mathrm{Th} 2$ cells play little or no role in its maintenance.

When Ascaris larvae reached the lungs of allergic mice, they found a marked IL-33/CD4 ${ }^{+}$type 2-dominated eosinophilic environment with elevated levels of EPO in the lung tissue, which was not observed in nonallergic but Ascaris-infected mice. In addition to eosinophil activation and degranulation, the release of eosinophil extracellular traps (EETs) may be an additional mechanism of killing or immune modulation, as already demonstrated for neutrophils (69) in a process termed NETosis (70) that can contribute to antimicrobial defense (71). Indeed, it has been shown that eosinophils from patients with allergic bronchopulmonary aspergillosis induce the release of EETs upon stimulation with the fungus Aspergillus fumigatus (72). Moreover, extracellular DNA traps generated by eosinophils have also been demonstrated in human atopic asthmatic airways $(73,74)$.

Finally, in the absence of HDM stimulation, Ascaris-infected mice demonstrated type 2-dominated lung inflammation, but only after $18 \mathrm{dpi}$. It has been suggested that this response in a primary helminth infection plays a key role in tissue remodeling and prevention of reinfection (75). Huang et al. (76) suggested that a primary infection with the helminth Trichinella spiralis induces 

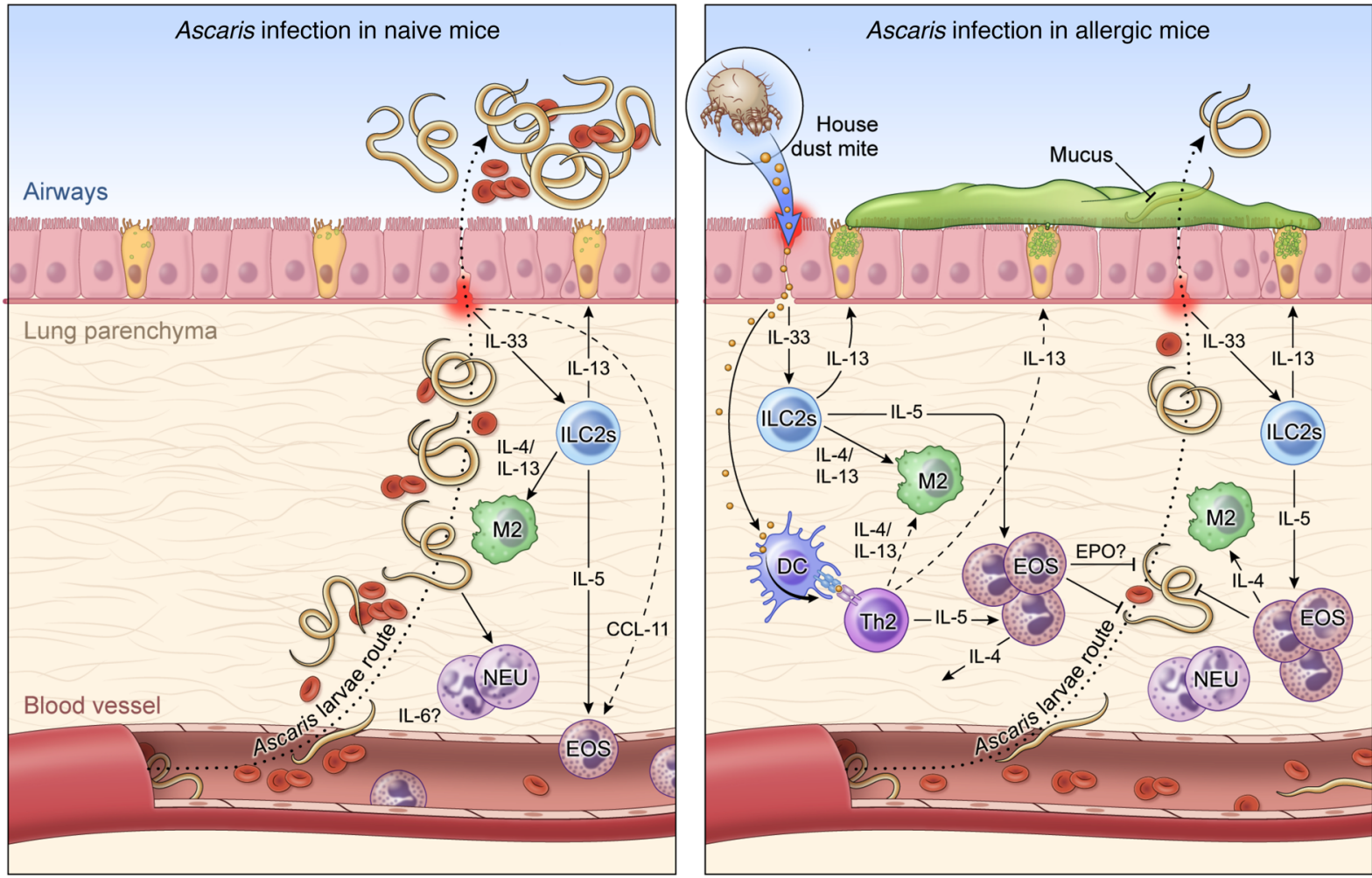

Figure 8. Working hypothesis model. Left: In a primary exposure to Ascaris parasites, after penetrating the intestine at the level of the cecum or proximal colon, the infective L3-stage larvae migrate through the portal vessels to the liver and subsequently to the lungs in their quest to reach the airways. Once in the lungs they migrate through the parenchyma, leading to a marked influx of neutrophils and correlated levels of IL-6, and penetrate into the alveolar spaces, causing bleeding and mechanical damage in the organ. These migrating Ascaris larvae, while growing in size toward the molting to L4 stages of biological development, induce a local inflammatory response in the lungs with a signature type 2 response, initially by early IL-5 levels, and later by IL- 4 and IL-13 levels, culminating in the differentiation of M2 macrophages and eosinophilia in the tissue. However, this robust type 2 response is only fully mounted when most of the larvae have reached the airways, allowing the establishment of a chronic and long-standing infection. Right: HDM allergic sensitization prior to infection with Ascaris induces a robust Th2-dominated inflammatory response in the lung characterized by an increase in both IL-5/ IL-13-producing type 2 innate lymphoid cells (ILC2s) and eosinophils. This allergen-driven inflammation in the lungs leads to an IL-4- and IL-13-rich environment that drives the differentiation of lung macrophages toward the M2 phenotype expressing arginase-1. When the Ascaris larvae migrate from the circulation to the lung tissue and airways in this HDM-sensitized environment, they encounter an eosinophil-dominated type 2 response, which leads to a $70 \%$ reduction in the number of lung-stage Ascaris larvae and a profound larval developmental arrest, allowing the reduction of intensity and burden of disease, inducing lower bleeding and mechanical damage in the tissue during their migration.

an eosinophil-dominant protective immunity in tissue of the host against reinfection. Moreover, it has been recently demonstrated that multiple exposures to Ascaris parasites in mice induced a remarkably protective lung-specific mixed type 2 and type 17 immune response associated with elevated number of eosinophils in the lung tissue and airways (77).

Indeed, we have previously shown by using cells from Loa loa-infected travelers, who present clinically with allergic-type symptoms much more frequently than those born and bred in Loa loa-endemic regions of the world $(78,79)$ and who had evidence of HDM allergic sensitization prior to the acquisition of their filarial infection, that there was a marked expansion of parasite antigen-specific $\mathrm{CD} 4^{+} \mathrm{Th} 2$ cells that were in turn associated with marked elevation of IgE and eosinophilia, in comparison with nonallergic but Loa loa-infected patients (39). Like these travelers, our data from this murine system suggest that allergic sensitization coincident with helminth infection drives an exaggerated eosinophil-rich pulmonary type 2 immune response in the lungs, mediated predominantly by the allergic sensitization that occurs prior to the development of the Ascaris-specific response in the lung. This in turn limits helminth parasite numbers. It is very likely that HDM allergic sensitization acts not unlike a primary Ascaris infection, such that a lung-specific type 2-mediated eosinophildependent helminth larval killing in the tissue occurs and limits (like a secondary infection) parasite numbers. Studies to increase understanding of the mechanisms by which HDM-driven eosinophils are activated and drive helminth larval killing are under way.

\section{Methods}

Mice. Wild-type (WT) BALB/c mice (male, 8 weeks old; Taconic Farm) were used throughout the study. $\triangle$ dblGATA mice (male, 8 weeks old) were provided by Helene Rosenberg, Laboratory of Allergic Diseases, National Institute of Allergy and Infectious Diseases, NIH, and bred in-house at the NIH Animal Facility.

HDM-induced allergic inflammation. Mice were anesthetized with isoflurane and sensitized intranasally with $200 \mu \mathrm{g}$ in $30 \mu \mathrm{L}$ of Dermatophagoides pteronyssinus HDM extract (Greer Laboratories) at day 0 and day 7. At days 14, 16, and 18, mice were given $50 \mu \mathrm{g}$ HDM extract 


\section{Table 1. Key antibodies}

\begin{tabular}{lcc} 
Antibody & Source & Catalog number \\
\hline APC-eFluor 780 anti-mouse TCR- $\beta$ (clone H57-597) & eBioscience & $47-5961-82$ \\
PerCP-Cy5.5-anti-mouse CD4 (clone RM4-5) & BD Pharmingen & 550954 \\
FITC-anti-mouse CD45 (clone 30-F11) & BioLegend & 103108 \\
BV605-anti-mouse Thy1.2 (clone 53-2.1) & BioLegend & 140318 \\
BV421-streptavidin & BioLegend & 405225 \\
\hline PE-Cy7-anti-mouse IFN- $\gamma$ (clone XMG1.2) & eBioscience & $25-7311-82$ \\
\hline PE-anti-mouse IL-13 (clone eBio13A) & eBioscience & $12-7133-82$ \\
\hline AF 700-anti-mouse IL-17A (clone TC11-18H10.1) & BioLegend & 506914 \\
\hline APC-anti-mouse IL-5 (clone TRFK5) & BD Pharmingen & 554396 \\
\hline Biotin-TER119 (clone TER-119) & eBioscience & $13-5921-82$ \\
\hline Biotin-CD19 (clone MB19-1) & eBioscience & $13-0191-85$ \\
\hline Biotin- $\gamma \delta$ STR (clone eBiogl3) & eBioscience & $13-5711-85$ \\
Biotin-Cr1 (clone RB6-8C5) & eBioscience & $13-5931-85$ \\
Biotin-CD11c (clone N418) & eBioscience & $13-0114-85$ \\
Biotin-CD11b (clone M1/70) & eBioscience & $13-0112-85$ \\
Biotin-CD49b (clone DX5) & eBioscience & $13-5971-85$ \\
\hline Biotin-TCR- $\beta$ (clone H57-597) & eBioscience & $13-5961-82$ \\
\hline BV605-anti-mouse CD11b (clone M1/70) & BioLegend & 101257 \\
PE-Cy7-anti-mouse F4/80 (clone BM8) & BioLegend & 123114 \\
\hline FITC-anti-mouse CD11c (clone HL3) & BD Pharmingen & 553801 \\
V500-anti-mouse MHC-II (clone M5/114.15.2) & BD Horizon & 562366 \\
APC-Cy7-anti-mouse Ly6C (clone AL-21) & BD Pharmingen & 560596 \\
PE-anti-mouse Siglec-F (clone E50-2440) & BD Pharmingen & 552126 \\
\hline PE-Texas red-anti-mouse Ly6C (clone 1A8) & BD Horizon & 562700 \\
\hline FITC-anti-mouse CD8b (clone eBioH35-17.2) & Invitrogen & $11-0083-85$ \\
\hline
\end{tabular}

in a volume of $30 \mu \mathrm{L}$ intranasally. Mice were infected with Ascaris at day 18 , immediately after the last sensitization with HDM by oral gavage. Tissues were examined immunologically at day 23 ( 5 dpi; liver and lungs), day 26 (8 dpi; lungs and BAL), and day 36 (18 dpi; lungs).

Parasite infection and parasitological analysis. Adult Ascaris suum worms were harvested from pigs at a Brazilian slaughterhouse (Belo Horizonte). Parasite eggs were isolated from female uteri through gentle mechanical maceration, purified by straining, and cultured to embryonation in $0.2 \mathrm{M} \mathrm{H}_{2} \mathrm{SO}_{4}$ as described by Boes et al. (80). On day 100 of culture, which is the peak of larva infectivity (81), the fully embryonated eggs were used for experimental infections. Mice were inoculated through the intragastric route with 2500 fully embryonated eggs. The parasite burden was evaluated based on the total number of larvae recovered after 5 days in the liver, after 5 and 8 days in the lungs, and after 8 days in the BAL fluid postinfection. The tissues were collected, sliced finely with scissors, and placed in a Baermann apparatus for 4 hours in PBS buffer at $37^{\circ} \mathrm{C}$. The larvae were recovered, fixed with formalin, and counted by microscopy.

Flow cytometry immunophenotyping. Lungs were digested with collagenase IV (Sigma-Aldrich) in RPMI culture media for 60 minutes at $37^{\circ} \mathrm{C}$, and single-cell suspensions were made by filtering through 100$\mu \mathrm{m}$ gauze (BD Biosciences). After addition of Percoll $40 \%$ and further ACK buffer for red blood cell lysis, leukocyte suspensions were counted (Countess II, Life Technologies) and incubated for 3 hours at $37^{\circ} \mathrm{C}, 5 \%$ $\mathrm{CO}_{2}$, in the absence of (media) or upon stimulation with $0.5 / 0.05 \mathrm{nM}$ of PMA/ionomycin (Sigma-Aldrich) and $10 \mu \mathrm{g} / \mathrm{mL}$ of brefeldin A. Cells were then stained using 2 panels of antibodies for flow cytometry (Table 1): $\mathrm{CD}^{+} \mathrm{T}$ cell polarization and innate lymphoid cell (ILC) subset panel, and myeloid lineage panel. Briefly, staining using the T cell polarization panel required 3 steps: The cells were stained with a LIVE/ DEAD marker (Fixable Blue, UV450, Thermo Fisher Scientific) and the biotinylated antibodies for lineage exclusion: TER119, CD19, $\gamma \delta$ TCR, Gr1, CD11c, CD49b, CD11b. Secondly, after washing with FACS buffer (PBS, 2\% FBS), antibodies against the extracellular markers CD45, TCR- $\beta$, Thy1.2, and streptavidin were used. After washing, cells were then fixed with $2 \%$ paraformaldehyde and permeabilized (Perm buffer, eBioscience), and finally stained with the following antibodies: CD4, IL-5, IL-13, IL-17A, and IFN- $\gamma$. The myeloid lineage panel was performed using a 2-step staining protocol: cells were stained with a LIVE/DEAD marker (Fixable Blue, UV450, Thermo Fisher Scientific) and the biotinylated antibodies for lineage exclusion: TCR- $\beta, \gamma \delta \mathrm{TCR}, \mathrm{CD} 49 \mathrm{~b}$, CD19. Secondly, after washing with FACS buffer, CD11c, Ly6C, CD11b, MHC-II, Siglec-F, Ly6G, and F4/80 were used. After washing, cells were then fixed with $2 \%$ paraformaldehyde. $\mathrm{CD} 4^{+} \mathrm{T}$ cell depletion was evaluated in the peripheral whole blood as well as in the lung tissue by flow cytometry analysis using TCR- $\beta, C D 4$, and CD8 surface staining. A description of the antibodies used, including the source and catalog/clone numbers, is included in Table 1. Data were acquired on an LSR Fortessa flow cytometer (BD Biosciences) and analyzed with FlowJo software (Tree Star).

Lung tissue chemokine, cytokine, cytokine receptor, and eosinophil peroxidase measurement. To evaluate the inflammatory mediators in the lung tissue homogenate, the bottom lobe of the right lung was homogenized for 2 cycles of 20 seconds at $5000 \mathrm{rpm}$ each using Precellys tubes with metal beads in $500 \mu \mathrm{L}$ of RIPA lysis buffer supplemented with protease inhibitor cocktail (ChemCruz) and 200 nM PMSF. Following centrifugation at $8000 \mathrm{~g}$ for 10 minutes at $4^{\circ} \mathrm{C}$, the supernatant was used to measure cytokines in the lung's homogenate. The cytokines IL-1 $\beta$, IL-3, IL-4, IL-5, IL-6, IL-13, IL-10, IL-33, IFN- $\gamma$, and TNF- $\alpha$ as well as the chemokines CCL-2 (MCP-1), CCL-5 (RANTES), CCL-11 (eotaxin), CXCL-5 (LIX), and CXCL-10 (IP-10) were measured using a commercial kit (Millipore). Lung IL-13R $\alpha 2$ protein concentration was determined by ELISA as previously described. High-protein-binding 96-well plates were coated with anti-IL-13R $\alpha 2$ $(1 \mu \mathrm{g} / \mathrm{mL})$ (R\&D Systems) in PBS overnight, and a biotinylated antimouse IL-13 (2 $\mu \mathrm{g} / \mathrm{mL}$; Centocor) was used for detection. Mouse eosinophil peroxidase (EPO) levels were measured in the lung homogenates using a sandwich ELISA kit (LSBio).

Histological examinations. The lobes of the left lung were fixed in $10 \%$ buffered formalin ( $\mathrm{pH} 7.2$ ) and embedded in paraffin. Sections (5 mm thick) were mounted on glass slides and stained with H\&E for inflammatory infiltration analysis, periodic acid-Schiff (PAS) for mucus production, or Masson's trichrome or Picrosirius for quantification of fibrotic process and collagen deposition. All images of the tissue sections were scanned using Scan Aperio (Leica), and the analyses were performed with specific algorithms for score quantification using Aperio e-Slide Manager (Leica). 
Morphometric analysis on the Ascaris larval stages. The development of different Ascaris larval stages was evaluated in BALB/c and $\triangle$ dblGATA preallergic and nonallergic mice, by morphometric measurement of the length and width of larvae recovered from the lung tissue at $5 \mathrm{dpi}$ and $8 \mathrm{dpi}$ as well as in the BAL at $8 \mathrm{dpi}$. After individual counting, larvae recovered from $\mathrm{HDM}^{+}$Ascaris ${ }^{-}$and $\mathrm{HDM}^{+}$Ascaris ${ }^{+}$ mice were pooled in separate wells, stretched by heat-killing, and fixed in 10\% buffered formalin. In vitro egg-hatched L3 larvae were also evaluated as previously described (82). Images of Ascaris larval stages were collected using a high-resolution bright-field confocal SP8 microscope (Leica). The morphometric analysis was performed using Imaris 9.0 software (Biplane).

RNA purification and quantitative PCR gene expression analysis. Lung tissue was homogenized in Trizol (Life Technologies) in a Precellys 24 homogenizer (Bertin Technologies). Total RNA was extracted with chloroform using a MagMax-96 Total RNA Isolation Kit (Qiagen) and reverse-transcribed to cDNA using SuperScript II Reverse Transcriptase (Life Technologies). Gene expression was quantified using Power SYBR Green PCR Master Mix (Applied Biosystems) by reverse transcriptase PCR on an ABI Prism 7900HT Sequence Detection System (Applied Biosystems). Expression of the target genes was described relative to RPLP2 mRNA levels. The specific primer pairs for each gene were: arginase-1, 5'-GGAAAGCCAATGAAGAGCTG-3' and 5'-GCTTCCAACTGCCAGACTGT-3'; Fizz-1, 5'-CCCTCCACTGTAACGAAGACTC-3' and 5'-CACACCCAGTAGCAGTCATCC-3'; Nos2, 5'-TGCCCCTTCAATGGTTGGTA-3' and 5'-ACTGGAGGGACCAGCCAAAT-3'; Rplp2, 5'-TACGTCGCCTCTTACCTGCT-3' and 5'-GACCTTGTTGAGCCGATCAT-3'; Muc5ac, 5'-CAGGACTCTCTGAAATCGTACCA-3' and 5'-AAGGCTCGTACCACAGGGA-3'.

In vivo $C D 4^{+} T$ cell depletion. Two hundred microliters of sterile PBS with $500 \mu \mathrm{g}$ of anti-CD4 (GK1.5) or $500 \mu \mathrm{g}$ of rat IgG2b isotype control (both from BioXCell) was given i.p. using 2 different protocols. The first protocol, "group day 0," received the i.p. injections on day 0 and days 7, 14, and 21 after HDM sensitization. The second protocol, "group day 18," received the injections at days 18 and 25 after the HDM sensitization (Figure 6A). The efficacy of the in vivo $\mathrm{CD} 4^{+} \mathrm{T}$ cell depletion was evaluated in the peripheral whole blood as well as in the lung tissue by flow cytometry analysis using TCR- $\beta$ and CD4 surface staining (Supplemental Figure 4).

$H D M$-specific antibody response. Antibody responses to HDM were evaluated by ELISA. Immunolon $4 \mathrm{HBX}$ plates were coated with $5 \mu \mathrm{g}$ / well of HDM extract (Greer Laboratories). Plates were incubated overnight at $4^{\circ} \mathrm{C}$ and, after washing, blocked with $200 \mu \mathrm{L}$ of $5 \%$ PBS-BSA for 1 hour at room temperature. Plates were washed 6 times with TweenPBS. Fifty microliters of mouse serum (1:500 for IgG1 and 1:1 for IgE in 1\% PBS-BSA) was added in duplicate and incubated for 1 hour at room temperature. Plates were washed and then incubated separately with biotinylated rat anti-mouse IgG1, IgE, and IgA (BD Pharmingen) (1:250 in 1\% PBS-BSA) for 1 hour at room temperature. Plates were washed and incubated with $50 \mu \mathrm{L}$ of streptavidin conjugated with HRP (1:200 in 1\% PBS-BSA for IgG1 and 1:100 in 1\% PBS-BSA for IgE) for 30 minutes at room temperature. After washing, TMB substrate TMB (3,3',5,5'-tetramethylbenzidine) was added (50 $\mu \mathrm{L} /$ well) and incubated for 5 minutes in the dark for IgG1 and 15 minutes for IgE. Twenty-five microliters of $2 \mathrm{~N} \mathrm{H}_{2} \mathrm{SO}_{4}$ was used to stop the reaction, and plates were read at absorbances of $450 \mathrm{~nm}$ and $550 \mathrm{~nm}$ on a multiplate reader (Molecular Devices).

Statistics. Unless stated otherwise, geometric means and 95\% confidence intervals were used as the measure of central tendency. The Kolmogorov-Smirnov test was used to determine whether data followed a normal distribution pattern. For nonparametric data, the Kruskal-Wallis test followed by Dunn's multiple-comparisons test was used for the analysis of tissue cytokine and chemokine profiles, the frequencies of ILCs and myeloid and T cells, and the comparison of parasite burden and larval development between different mouse strains or antibody treatments. The Mann-Whitney $U$ test was used to determine the differences between the variables associated with parasite burden in BALB/c mice and $\triangle \mathrm{dblGATA}$ separately. For the differences in gene expression, the nonparametric Wilcoxon matched-pairs test or the Mann-Whitney $U$ test was used for the analysis between $\mathrm{HDM}^{+}$Ascaris ${ }^{-}$mice and $\mathrm{HDM}^{+}$Ascaris ${ }^{+}$mice. Correlation analysis was performed using the Spearman rank test. Graph generation and statistical analysis were performed using Prism 7.0 for Windows (GraphPad Software Inc.), and differences were considered statistically significant when $P$ was less than 0.05 .

Study approval. The maintenance and use of animals were in accordance with the recommendations of the NIH Guide for the Care and Use of Laboratory Animals (National Academies Press, 2011). All animal experiments were approved by NIH Animal Care and Use Committee (Animal Study Protocol LPD-6). All efforts were made to minimize suffering and pain, as described in these approved protocols and guidelines.

\section{Author contributions}

PHGG, RQP, AR, SBA, JS, and EPK performed the experiments. PHGG, RQP, and TBN designed the experiments. PHGG, RQP, AR, SBA, JS, EPK, RTF, and TBN carried out analyses. PHGG wrote the paper; all authors edited the paper. RTF and TBN provided funding and reagents.

\section{Acknowledgments}

We are grateful to Dragana Jankovic from the Laboratory of Parasitic Diseases of the NIH for the motivation and for reviewing the work, and also Olena Kamanyeva from the Biological Imaging section of the Research Technologies Branch at the NIH (RTB/NIH) for the support in helminth larvae imaging. This study was supported by the Division of Intramural Research, NIH.

Address correspondence to: Thomas B. Nutman, Laboratory of Parasitic Diseases, Building 4 Room 211C, 4 Center Drive, National Institutes of Health, Bethesda, Maryland 20892-0425, USA. Phone:301.496.5399; Email: tnutman@niaid.nih.gov.
1. Nutman TB. Looking beyond the induction of Th2 responses to explain immunomodulation by helminths. Parasite Immunol. 2015;37(6):304-313.

2. Maizels RM, McSorley HJ. Regulation of the host immune system by helminth parasites. J Allergy
Clin Immunol. 2016;138(3):666-675.

3. Babu S, Nutman TB. Helminth-tuberculosis co-infection: an immunologic perspective. Trends Immunol. 2016;37(9):597-607.

4. King CL, et al. Immunologic tolerance in lymphatic filariasis. Diminished parasitespecific $\mathrm{T}$ and $\mathrm{B}$ lymphocyte precursor frequency in the microfilaremic state. JClin Invest. 1992;89(5):1403-1410.

5. Gazzinelli-Guimarães PH, et al. Concomitant 
helminth infection downmodulates the Vaccinia virus-specific immune response and potentiates virus-associated pathology. Int J Parasitol. 2017;47(1):1-10.

6. Daniłowicz-Luebert E, O’Regan NL, Steinfelder S, Hartmann S. Modulation of specific and allergy-related immune responses by helminths. J Biomed Biotechnol. 2011;2011:821578.

7. Smits HH, Yazdanbakhsh M. Chronic helminth infections modulate allergen-specific immune responses: protection against development of allergic disorders? Ann Med. 2007;39(6):428-439.

8. Sabin EA, Araujo MI, Carvalho EM, Pearce EJ. Impairment of tetanus toxoid-specific Th1-like immune responses in humans infected with Schistosoma mansoni. JInfect Dis. 1996;173(1):269-272.

9. Cooper PJ, Espinel I, Paredes W, Guderian RH, Nutman TB. Impaired tetanus-specific cellular and humoral responses following tetanus vaccination in human onchocerciasis: a possible role for interleukin-10. J Infect Dis. 1998;178(4):1133-1138.

10. McSorley HJ, et al. Suppression of inflammatory immune responses in celiac disease by experimental hookworm infection. PLoS One. 2011;6(9):e24092.

11. Cançado GG, et al. Hookworm products ameliorate dextran sodium sulfate-induced colitis in BALB/c mice. Inflamm Bowel Dis. 2011;17(11):2275-2286.

12. Zaccone P, Cooke A. Helminth mediated modulation of Type 1 diabetes (T1D). Int J Parasitol. 2013;43(3-4):311-318.

13. Hübner MP, et al. Helminth protection against autoimmune diabetes in nonobese diabetic mice is independent of a type 2 immune shift and requires TGF- $\beta$. J Immunol. 2012;188(2):559-568.

14. Chen Z, et al. Th2 and eosinophil responses suppress inflammatory arthritis. Nat Commun. 2016;7:11596.

15. Eichenberger RM, Sotillo J, Loukas A. Immunobiology of parasitic worm extracellular vesicles. Immunol Cell Biol. 2018;96(7):704-713.

16. Wu Z, Wang L, Tang Y, Sun X. Parasite-derived proteins for the treatment of allergies and autoimmune diseases. Front Microbiol. 2017;8:2164.

17. Eichenberger RM, et al. Hookworm secreted extracellular vesicles interact with host cells and prevent inducible colitis in mice. Front Immunol. 2018;9:850.

18. Cooper PJ. Interactions between helminth parasites and allergy. Curr Opin Allergy Clin Immunol. 2009;9(1):29-37.

19. Palmer LJ, Celedón JC, Weiss ST, Wang B, Fang $\mathrm{Z}, \mathrm{Xu}$ X. Ascaris lumbricoides infection is associated with increased risk of childhood asthma and atopy in rural China. Am J Respir Crit Care Med. 2002;165(11):1489-1493.

20. Hunninghake GM, et al. Sensitization to Ascaris lumbricoides and severity of childhood asthma in Costa Rica. JAllergy Clin Immunol. 2007;119(3):654-661.

21. Suzuki M, et al. Presensitization to Ascaris antigens promotes induction of mite-specific IgE upon mite antigen inhalation in mice. Allergol Int. 2016;65(1):44-51.

22. Weatherhead JE, et al. Ascaris larval infection and lung invasion directly induce severe allergic airway disease in mice. Infect Immun. 2018;86(12):e00533-18.

23. Maizels RM, Yazdanbakhsh M. Immune regulation by helminth parasites: cellular and molecular mechanisms. Nat Rev Immunol. 2003;3(9):733-744.

24. King CL, et al. Cytokine control of parasitespecific anergy in human urinary schistosomiasis. IL-10 modulates lymphocyte reactivity. J Immunol. 1996;156(12):4715-4721.

25. van den Biggelaar AH, et al. Decreased atopy in children infected with Schistosoma haematobium: a role for parasite-induced interleukin-10. Lancet. 2000;356(9243):1723-1727.

26. Yazdanbakhsh M, Wahyuni S. The role of helminth infections in protection from atopic disorders. Curr Opin Allergy Clin Immunol. 2005;5(5):386-391.

27. Satoguina JS, Weyand E, Larbi J, Hoerauf A. T regulatory-1 cells induce IgG4 production by B cells: role of IL-10. JImmunol. 2005;174(8):4718-4726.

28. Lin AA, Freeman AF, Nutman TB. IL-10 indirectly downregulates IL-4-induced IgE production by human B cells. Immunohorizons. 2018;2(11):398-406.

29. Allen JE, Maizels RM. Diversity and dialogue in immunity to helminths. Nat Rev Immunol. 2011;11(6):375-388.

30. Pulendran B, Artis D. New paradigms in type 2 immunity. Science. 2012;337(6093):431-435.

31. Lambrecht BN, Hammad H. The immunology of the allergy epidemic and the hygiene hypothesis. Nat Immunol. 2017;18(10):1076-1083.

32. Rainbird MA, Macmillan D, Meeusen EN. Eosinophil-mediated killing of Haemonchus contortus larvae: effect of eosinophil activation and role of antibody, complement and interleukin-5. Parasite Immunol. 1998;20(2):93-103.

33. Abraham D, et al. Immunoglobulin $\mathrm{E}$ and eosinophil-dependent protective immunity to larval Onchocerca volvulus in mice immunized with irradiated larvae. Infect Immun. 2004;72(2):810-817.

34. Venturiello SM, Giambartolomei GH, Costantino SN. Immune cytotoxic activity of human eosinophils against Trichinella spiralis newborn larvae. Parasite Immunol. 1995;17(11):555-559.

35. Behm CA, Ovington KS. The role of eosinophils in parasitic helminth infections: insights from genetically modified mice. Parasitol Today (Regul Ed). 2000;16(5):202-209.

36. Simons JE, Rothenberg ME, Lawrence RA. Eotaxin-1-regulated eosinophils have a critical role in innate immunity against experimental Brugia malayi infection. Eur J Immunol. 2005;35(1):189-197.

37. Klion AD, Nutman TB. The role of eosinophils in host defense against helminth parasites. J Allergy Clin Immunol. 2004;113(1):30-37.

38. Galioto AM, Hess JA, Nolan TJ, Schad GA, Lee JJ, Abraham D. Role of eosinophils and neutrophils in innate and adaptive protective immunity to larval strongyloides stercoralis in mice. Infect Immun. 2006;74(10):5730-5738.

39. Gazzinelli-Guimaraes PH, Bonne-Annee S, Fujiwara RT, Santiago HC, Nutman TB. Allergic sensitization underlies hyperreactive antigen-specific $\mathrm{CD} 4{ }^{+} \mathrm{T}$ cell responses in coincident filarial infection. JImmunol. 2016;197(7):2772-2779.

40. Murrell KD, Eriksen L, Nansen P, Slotved HC, Rasmussen T. Ascaris suum: a revision of its early migratory path and implications for human ascariasis. J Parasitol. 1997;83(2):255-260.

41. Slotved HC, Eriksen L, Murrell KD, Nansen P. Early Ascaris suum migration in mice as a model for pigs. J Parasitol. 1998;84(1):16-18.

42. Lewis R, Behnke JM, Stafford P, Holland CV. The development of a mouse model to explore resistance and susceptibility to early Ascaris suum infection. Parasitology. 2006;132(pt 2):289-300.

43. Cooper PJ, et al. Human infection with Ascaris lumbricoides is associated with a polarized cytokine response. J Infect Dis. 2000;182(4):1207-1213.

44. Enobe CS, Araújo CA, Perini A, Martins MA, Macedo MS, Macedo-Soares MF. Early stages of Ascaris suum induce airway inflammation and hyperreactivity in a mouse model. Parasite Immunol. 2006;28(9):453-461.

45. Bach JF. The effect of infections on susceptibility to autoimmune and allergic diseases. $N$ Engl J Med. 2002;347(12):911-920.

46. Feasey N, Wansbrough-Jones M, Mabey DC, Solomon AW. Neglected tropical diseases. Br Med Bull. 2010;93:179-200.

47. Pawankar R, Canonica GW, Holgate ST, Lockey RF. Allergic diseases and asthma: a major global health concern. Curr Opin Allergy Clin Immunol. 2012;12(1):39-41.

48. Santiago HC, Nutman TB. Human helminths and allergic disease: the hygiene hypothesis and beyond. Am J Trop Med Hyg. 2016;95(4):746-753.

49. Gazzinelli-Guimaraes PH, Nutman TB. Helminth parasites and immune regulation. F1000Res. 2018;7:F1000 Faculty Rev-1685.

50. Maizels RM. Infections and allergy - helminths, hygiene and host immune regulation. Curr Opin Immunol. 2005;17(6):656-661.

51. Mahanty S, Nutman TB. Immunoregulation in human lymphatic filariasis: the role of interleukin 10. Parasite Immunol. 1995;17(8):385-392.

52. Larson D, et al. Chronic helminth infection reduces basophil responsiveness in an IL-10-dependent manner. JImmunol. 2012;188(9):4188-4199.

53. King CL, et al. Cytokine control of parasitespecific anergy in human lymphatic filariasis. Preferential induction of a regulatory $\mathrm{T}$ helper type 2 lymphocyte subset. JClin Invest. 1993;92(4):1667-1673.

54. Navarro S, et al. Hookworm recombinant protein promotes regulatory $\mathrm{T}$ cell responses that suppress experimental asthma. Sci Transl Med. 2016;8(362):362ra143.

55. Hammad H, Chieppa M, Perros F, Willart MA, Germain RN, Lambrecht BN. House dust mite allergen induces asthma via Toll-like receptor 4 triggering of airway structural cells. Nat Med. 2009;15(4):410-416.

56. Salazar F, Ghaemmaghami AM. Allergen recognition by innate immune cells: critical role of dendritic and epithelial cells. Front Immunol. 2013;4:356.

57. Kondo Y, et al. Administration of IL-33 induces airway hyperresponsiveness and goblet cell hyperplasia in the lungs in the absence of adaptive immune system. Int Immunol. 2008;20(6):791-800.

58. Kurowska-Stolarska M, et al. IL-33 amplifies the polarization of alternatively activated macrophages that contribute to airway inflammation. JImmunol. 2009;183(10):6469-6477. 
59. Lei Y, Boinapally V, Zoltowska A, Adner M, Hellman L, Nilsson G. Vaccination against IL-33 inhibits airway hyperresponsiveness and inflammation in a house dust mite model of asthma. PLoS One. 2015;10(7):e0133774.

60. Wynn TA. IL-13 effector functions. Annu Rev Immunol. 2003;21:425-456.

61. Zhu Z, et al. Pulmonary expression of interleukin-13 causes inflammation, mucus hypersecretion, subepithelial fibrosis, physiologic abnormalities, and eotaxin production. J Clin Invest. 1999;103(6):779-788.

62. Rahaman SO, Sharma P, Harbor PC, Aman MJ, Vogelbaum MA, Haque SJ. IL-13R(alpha)2, a decoy receptor for IL-13 acts as an inhibitor of IL-4-dependent signal transduction in glioblastoma cells. Cancer Res. 2002;62(4):1103-1109.

63. Wood N, et al. Enhanced interleukin (IL)-13 responses in mice lacking IL-13 receptor alpha 2. JExp Med. 2003;197(6):703-709.

64. Chiaramonte MG, et al. Regulation and function of the interleukin 13 receptor alpha 2 during a T helper cell type 2-dominant immune response. JExp Med. 2003;197(6):687-701.

65. Deepak P, Sanjay K, Acharya A. IL-13 R $\alpha 2-$ mediated interleukin-13 neutralization represses in vivo progressive growth of a T-cell lymphoma. J Exp Clin Cancer Res. 2007;26(3):347-352.

66. O'Connell AE, et al. Major basic protein from eosinophils and myeloperoxidase from neutrophils are required for protective immunity to Strongyloides stercoralis in mice. Infect Immun. 2011;79(7):2770-2778.
67. Hamann KJ, Gleich GJ, Checkel JL, Loegering DA, McCall JW, Barker RL. In vitro killing of microfilariae of Brugia pahangi and Brugia malayi by eosinophil granule proteins. JImmunol. 1990;144(8):3166-3173.

68. Filbey KJ, et al. Intestinal helminth infection promotes IL-5- and CD4 ${ }^{+} \mathrm{T}$ cell-dependent immunity in the lung against migrating parasites. Mucosal Immunol. 2019;12(2):352-362.

69. Bonne-Année S, et al. Extracellular traps are associated with human and mouse neutrophil and macrophage mediated killing of larval Strongyloides stercoralis. Microbes Infect. 2014;16(6):502-511.

70. Ueki S, et al. Eosinophil extracellular trap cell death-derived DNA traps: their presence in secretions and functional attributes. JAllergy Clin Immunol. 2016;137(1):258-267.

71. Yousefi S, et al. Catapult-like release of mitochondrial DNA by eosinophils contributes to antibacterial defense. Nat Med. 2008;14(9):949-953.

72. Muniz VS, et al. Eosinophils release extracellular DNA traps in response to Aspergillus fumigatus. JAllergy Clin Immunol. 2018;141(2):571-585.e7.

73. Dworski R, Simon HU, Hoskins A, Yousefi S. Eosinophil and neutrophil extracellular DNA traps in human allergic asthmatic airways. JAllergy Clin Immunol. 2011;127(5):1260-1266.

74. Choi Y, Le Pham D, Lee DH, Lee SH, Kim SH, Park HS. Biological function of eosinophil extracellular traps in patients with severe eosinophilic asthma. Exp Mol Med. 2018;50(8):104.

75. Maizels RM, Pearce EJ, Artis D, Yazdanbakhsh
M, Wynn TA. Regulation of pathogenesis and immunity in helminth infections. J Exp Med. 2009;206(10):2059-2066.

76. Huang L, et al. Eosinophils mediate protective immunity against secondary nematode infection. J Immunol. 2015;194(1):283-290.

77. Nogueira DS, et al. Multiple exposures to Ascaris suum induce tissue injury and mixed Th2/Th17 immune response in mice. PLoS Negl Trop Dis. 2016;10(1):e0004382.

78. Herrick JA, et al. Eosinophil-associated processes underlie differences in clinical presentation of loiasis between temporary residents and those indigenous to Loa-endemic areas. Clin Infect Dis. 2015;60(1):55-63.

79. Steel C, Varma S, Nutman TB. Regulation of global gene expression in human Loa loa infection is a function of chronicity. PLoS Negl Trop Dis. 2012;6(2):e1527.

80. Boes J, Eriksen L, Nansen P. Embryonation and infectivity of Ascaris suum eggs isolated from worms expelled by pigs treated with albendazole, pyrantel pamoate, ivermectin or piperazine dihydrochloride. Vet Parasitol. 1998;75(2-3):181-190.

81. Gazzinelli-Guimarães PH, et al. Parasitological and immunological aspects of early Ascaris spp. infection in mice. Int J Parasitol. 2013;43(9):697-706.

82. Ponce-Macotela M, Rodríguez-Caballero A, Peralta-Abarca GE, Martínez-Gordillo MN. A simplified method for hatching and isolating Toxocara canis larvae to facilitate excretorysecretory antigen collection in vitro. Vet Parasitol. 2011;175(3-4):382-385. 